\title{
La regulación del autoconsumo de electricidad en un nuevo entorno social y tecnológico*
}

Alejandro D. Leiva López

DOI: https://doi.org/10.47623/ivap-rvap.110.2018.1.04

\begin{abstract}
Sumario: -I. Introducción. Contexto político-económico.-II. El autoconsumo de electricidad. 1. Concepto y marco jurídico. La figura del "prosumer». 2. Notas diferenciadoras respecto del modelo tradicional de suministro eléctrico. 3. Modalidades de autoconsumo. 3.1. Autoconsumo aislado. 3.2. El suministro con autoconsumo (tipo 1). 3.3. La producción con autoconsumo (tipo 2). 4. Cuestiones de interés en un nuevo entorno social y tecnológico. 4.1. Las redes inteligentes y el almacenamiento de energía. 4.2. El deber de mantenimiento de los costes fijos del sistema por parte del autoconsumidor. A propósito de la sobrecapacidad. 4.3. El auge de la industria fotovoltaica y la necesidad de que el autoconsumidor esté conectado a la red. - III. Conflictos competenciales en materia de autoconsumo: Estado vs CCAA. 1. Aspectos generales. 2. Posición de las Comunidades Autónomas. 2.1. Materias específicas objeto de conflicto. 2.1.1. Objeto y ámbito de aplicación. 2.1.2. Condiciones técnicas y administrativas para la modalidad tipo 1. 2.1.3. Potencia instalada. 2.1.4. Calidad del servicio. 2.1.5. Conexión a la red. 2.1.6. Contratos de acceso e información. 2.1.7. Registro de instalaciones. 2.1.8. Instalaciones de cogeneración. 2.1.9. Autorización de vertido excedente. 2.2. En especial: el autoconsumo compartido o vecinal. 3. Posición del Tribunal Constitucional. A propósito de la STC 68/2017. 3.1. Sobre el Registro de autoconsumo. 3.2. Sobre el autoconsumo compartido.-IV. Conclusiones. -V. Bibliografía.
\end{abstract}

\section{Introducción. Contexto político-económico}

Vivimos en un mundo cada vez más globalizado y con un modelo energético inestable desde el punto de vista medioambiental (por todos es conocido el efecto negativo severo del cambio climático) e incluso, en ocasiones,

\footnotetext{
* Trabajo realizado en el marco del proyecto I+D «Sostenibilidad energética y entes locales: incidencia del nuevo paquete energético de la Unión Europea" (DER2017-86637-C3-2-P), Ministerio de Economía y Competitividad, Programa Estatal de Fomento de la Investigación Científica y Técnica de Excelencia, Subprograma Estatal de Generación del Conocimiento, Convocatoria 2017.
} 
económico (véase cómo el sistema ha adolecido durante varios años de un déficit tarifario como consecuencia del régimen de primas a renovables(1)).

El sector eléctrico se encuentra en un complejo escenario donde los recursos fósiles son limitados y la energía nuclear no parece ofrecer condiciones de seguridad óptimas. Sin embargo, y afortunadamente, emergen fuentes de energía renovables que tratan de colmar las deficiencias de este modelo productivo(2).

Por su parte, el autoconsumo de electricidad experimenta grandes avances tecnológicos $y$, de partida, debe convertirse en una tecnología competitiva capaz de cuestionar la continuidad del sistema tradicional de suministro 0 , al menos, de tener un intenso carácter complementario. Así, el precio competitivo de algunas tecnologías (como los paneles fotovoltaicos) y los avances en materia de dispositivos de almacenamiento (principalmente baterías para uso doméstico) permite que cada vez sean mayores los intereses del usuario eléctrico en esta forma de generación distribuida; sin perder de vista que, a día de hoy, no puede almacenarse electricidad en grandes cantidades (3).

Sin embargo, y siendo objeto principal de estudio, son muchos los que afirman que la regulación del autoconsumo parece caminar en otro sentido, existiendo dudas fundadas acerca de si el legislador favorece o, por el contrario, obstaculiza la implementación efectiva de este mecanismo de autogeneración de electricidad.

En la Cumbre del Clima de París o COP21 (celebrada entre 30 de noviembre y 11 de diciembre de 2015) (4) los Estados integrantes, bajo la supervisión de EE.UU. y China, manifiestan un interés común y firme por hacer frente al cambio climático, dejando atrás las poco efectivas declaraciones de intereses que acontecieron en Kioto (1997) y Copenhague (2009). Así, la COP21 de-

(1) A mayor abundamiento, y específicamente acerca de uno de los episodios más significativos de la progresiva suspensión del régimen de ayudas a la producción renovable, vid. DEL GUAYO CASTIELLA, Íñigo, "Seguridad jurídica y cambios regulatorios (A propósito del Real Decreto-ley núm. 1/2012, de 27 de enero, de suspensión de los procedimientos de preasignación de retribución y de supresión de las primas para nuevas instalaciones de producción de energía eléctrica mediante fuentes de energía renovables", en Revista Española de Derecho Administrativo, núm. 156, 2012, págs. 217-254.

(2) DEL GUAYO CASTIELLA, Íñigo, DOMINGO LÓPEZ, Enrique y LEIVA LÓPEZ, Alejandro D., «Régimen jurídico del auto-consumo en España. A propósito del Real Decreto 900/2015, de 9 de octubre», en Riesgo Regulatorio en las Energías Renovables II, ed. Aranzadi, 2017, págs.106-107.

(3) A propósito de los precios competitivos que ofrece la empresa Tesla para baterías de uso doméstico destinadas al autoconsumo, vid. CHEVALIER, Michael, "¿Revolucionará Tesla la energía?: El fabricante estadounidense de coches eléctricos se diversifica con la fabricación de baterías de uso doméstico", en Alternativas económicas, núm.28 (septiembre), 2015, págs. 24-25 y, como obra de referencia en la materia, SIOSHANSI, Fereidoon P., en Future of Utilities. Utilities of the Future, 2016, ed. ACADEMIC PRESS, sobre la aparición de un nuevo modelo energético basado en el autoconsumo, las redes inteligentes y los sistemas de almacenamiento de electricidad a cargo de baterías y otras tecnologías.

(4) 21. ${ }^{\text {a }}$ Conferencia de las Partes de la Convención Marco de las Naciones Unidas sobre el Cambio Climático de 2015 (COP21/CMP11), también conocida como «París 2015». 
fine como prioritario el impulso de las energías renovables, otorgando un papel protagonista a la energía solar(5), y del autoconsumo de electricidad, especialmente a través de instalaciones fotovoltaicas. Es por ello que muchas de las reflexiones aquí vertidas se hacen desde la panorámica del autoconsumo fotovoltaico, siendo ésta la tecnología sobre la que el avance ingenieril y los precios competitivos se proyectan de forma más notoria (6).

El objetivo principal de la reunión de París de mantener el calentamiento global por debajo de los dos grados centígrados conecta con la necesidad de que acontezca un cambio de modelo económico encaminado a eliminar gradualmente los combustibles fósiles a favor de una implantación efectiva de las energías renovables, donde el papel asumido por el prosumer(7) es clave. El aumento deliberado de la temperatura del planeta, si no se adoptan medidas efectivas para su mitigación, provocará que cada vez necesitemos más energía y, por tanto, mayor producción con cargo a fuentes contaminantes fósiles; lo que ocasiona un impacto ambiental muy negativo. En la COP21 se concluye que no hay tiempo para formular meras declaraciones de intenciones, que ya no tiene cabida la indecisión que imperaba en cumbres como la de 2009 y que, consecuentemente, los estados tienen la obligación moral de actuar y transformar el actual modelo de desarrollo en un nuevo paradigma capitaneado por las energías renovables, la eficiencia energética y el autoconsumo de electricidad.

A nivel comunitario, la nueva propuesta de la Comisión Europea de Paquete de Energía (conocido como "Winter Package») persigue garantizar al ciudadano el acceso al autoconsumo sin cargas o procedimientos que no reflejen el coste real de la actividad, así como también promueve el denominado autoconsumo compartido.

Por su parte, en España, el 9 de octubre de 2015 (solo unas semanas antes de celebrarse la COP21), el Consejo de Ministros aprobó el Real Decreto 900/2015, por el que se regulan las condiciones administrativas, técnicas y económicas de las modalidades de suministro de energía eléctrica con autoconsumo y de producción con autoconsumo (8).

(5) Vid. cómo, en el seno de la COP21, las asociaciones renovables líderes crean el "Global Solar Council", con la finalidad de promover la rápida implementación de la energía solar a través de un marco de cooperación y formación mundial. Destacadamente, la copresidencia de este consejo corre a cargo del director general de la Unión Española Fotovoltaica (UNEF), José Donoso.

(6) Sobre las ventajas competitivas de autoconsumo mediante instalaciones fotovoltaicas, vid. DEL GUAYO CASTIELLA, Íñigo, DOMINGO LÓPEZ, Enrique y LEIVA LÓPEZ, Alejandro D., «Régimen jurídico del...", op. cit., págs. 110-112.

(7) Acrónimo formado por la fusión original de las palabras inglesas "productor» y "consumer», para referirnos al nuevo papel que tiene el usuario de consumir y, además, producir su propia energía. En castellano nos referimos al prosumidor. Se trata de una figura conocida no sólo en el ámbito energético sino también en otros campos como la informática o la agricultura.

(8) BOE núm. 243, de 10 de octubre. 
La doctrina mayoritaria ha calificado esta norma como un «impuesto al sol", así como también lo han hecho los sindicatos (CCOO y UGT), las asociaciones de consumidores (ADICAE, ASGECO, FACUA u OCU), grupos ecologistas (GREENPEACE) y asociaciones empresariales (AIFOC, ANPIER, APPA Fotovoltaica, UNEF o PIMEC) (9).

Es por ello que ofrecemos un análisis de las distintas figuras de autoconsumo definidas en el RD 900/2015, poniendo en una balanza, de un lado, la creación de un peaje o posible uimpuesto al sol" para aquellos que deciden invertir en tecnologías de autoconsumo y, de otro, la necesidad de que todos los usuarios eléctricos, incluido el autoconsumidor, contribuyan a los costes de mantenimiento del sistema.

Además, analizamos la posición más reciente de la jurisprudencia en relación a los conflictos competenciales que suscita el RD 900/2015, con especial atención a la figura del autoconsumo compartido o vecinal.

La regulación jurídica de sectores estratégicos como el eléctrico (conocida como regulación económica o regulación para la competencia) presenta una naturaleza económica, sociológica, política y jurídica que definen su carácter predominantemente interdisciplinar. Se trata de una intervención directa del Estado en la economía, en los sectores estratégicos regulados (no solo el eléctrico, sino también otros como el sector del transporte aéreo y ferroviario o el de las telecomunicaciones) valiéndose de mecanismos de control social que afectan a todos los aspectos del comportamiento; una supervisión que se encomienda normalmente a una agencia pública especializada e independiente. (10) Por tanto, si conexionamos todo ello con las especificidades del sector de la electricidad, y concretamente con las inherentes a la figura del autoconsumo que es objeto de estudio, la ardua tarea que se encomienda al Estado es la de controlar y accionar en cada momento la válvula que libera el vapor de una olla (mercado eléctrico) cuando la presión supera ciertos límites, en la búsqueda de un equilibrio entre los intereses de los operadores eléctricos y los del consumidor final o, para el caso que nos ocupa, del autoconsumidor.

(9) Destaca el manifiesto "Un compromiso de la sociedad a favor del derecho cívico al autoconsumo de energía». Aprobado el 27 de julio de 2015 y siendo partícipes la práctica totalidad de formaciones políticas, las asociaciones de consumidores, empresariales y sindicales, ecologistas, así como los distintos movimientos sociales. En este escrito defienden que el autoconsumo es un derecho cívico y elemental para la configuración de un nuevo modelo energético que haga frente al cambio climático. En definitiva, los firmantes piden la retirada de lo que, en esa fecha, era todavía un proyecto de Real Decreto.

(10) BALDWIN, Robert, SCOTT, Colin y HOOD, Christopher, en A Reader on Regulation, Ed. Oxford University Press, 1998, págs. 56-70. 


\section{El autoconsumo de electricidad}

\section{Concepto y marco jurídico. La figura del «prosumen»}

Estamos ante un nuevo escenario en lo que al modo de generación de electricidad se refiere y ello conduce a convertirnos en prosumidores, esto es, consumidores $y$, al mismo tiempo, productores o generadores de energía (piénsese, por ejemplo, en el usuario que tiene su propia instalación fotovoltaica en el tejado de su vivienda), lo que nos hace partícipes en la toma de decisiones que versen sobre cuándo, cómo y qué energía consumir; sin olvidar la conexión que debe existir, en este nuevo marco regulativo, entre la figura del prosumidor, las redes inteligentes y el almacenamiento de electricidad (destacan los avances tecnológicos de la empresa Tesla en baterías de almacenamiento de electricidad para uso doméstico). En este sentido, el legislador no puede desatender los avances que brindan las ciencias ingenieriles $y$, por consiguiente, tiene que velar por que este trilema - prosumidor, redes inteligentes y almacenamiento - se desarrolle en absoluta armonía(11).

Acerca de esta doble figura (consumidor-productor) cabe significar que fue intencionadamente omitida por el Real Decreto-ley 13/2012, de 30 de marzo, por el que se transponen directivas en materia de mercados interiores de electricidad y gas y en materia de comunicaciones electrónicas, y por el que se adoptan medidas para la corrección de las desviaciones por desajustes entre los costes e ingresos de los sectores eléctricos y gasista (12). La citada norma modificó las definiciones de productor y consumidor contenidas en la Ley 54/1997, de 27 de noviembre, del Sector Eléctrico(13), bajo la premisa de que el "autoconsumidor" no se podía considerar "productor" o "autoproductor", ya que no venden electricidad excedentaria, sino que adquieren derechos de consumo diferidos, de ma-

(11) Sobre estas cuestiones conceptuales se pronuncia el Dr. Fereidoon P. Sioshansi, director de la consultora de servicios energéticos Menlo Energy Economics (San Francisco, EEUU), en su ponencia sobre la experiencia estadounidense en la materia, con ocasión de una Jornada sobre Generación Distribuida y Autoconsumo organizada por el Club Español de la Energía (ENERCLUB) y celebrada en Madrid el 3 de febrero de 2016. El ponente trae a colación conceptos relevantes e innovadores sobre almacenamiento de electricidad, no necesariamente a cargo de baterías, y anuncia que serán objeto de estudio exhaustivo en su obra Future of utilities. Utilities of the future, que en ese momento estaba en proceso de publicación. En la citada obra el autor trata de evidenciar cómo la nueva empresa energética del futuro, si la regulación lo permite, será nuestro propio hogar. En definitiva, un nuevo modelo, alejado del modelo tradicional energético no sostenible, que deberá configurarse con precisión y atendiendo no sólo a las ventajas sociales que produce, sino también a los problemas de intermitencia y de costes conexos a las nuevas tecnologías de autoconsumo y las redes inteligentes.

(12) $B O E$ núm. 78 de 31 de marzo.

(13) BOE núm. 285, de 28 de noviembre. 
nera que esta figura de autoconsumidor no debía estar sujeta a las obligaciones jurídicas exigidas al resto de productores.

Sin embargo, en la actualidad la Ley 24/2013, de 26 de diciembre, del Sector Eléctrico (en adelante, LSE) (14) dedica específicamente su artículo nueve a la regulación del autoconsumo de energía eléctrica y, en desarroIlo de esta figura, el RD 900/2015 altera este matiz conceptual observado SUPRA creando la figura del "autoproductor" y definiendo para el que vierte su energía sobrante, y que por consiguiente adquiere derechos de consumo diferidos, una serie de obligaciones estrechamente ligadas a la figura del productor tradicional. Así, destacan la obligación de constituirse en empresa, darse de alta en el Impuesto de Actividades Económicas o hacer declaraciones trimestrales de IVA. Vemos, en definitiva, cómo el legislador rompe un marco conceptual predefinido y crea una figura más empresarial de autoconsumidor que vierte su excedente a la red.

En definitiva, el autoconsumo requiere de una intervención o participación activa por parte del usuario eléctrico y es por ello que presenta un carácter en cierto modo educativo. En este sentido, el prosumidor, al autoproducir gran parte de la electricidad que necesita, se va a concienciar del coste eléctrico que ésta implica y, por consiguiente, adoptará una actitud proactiva en el empleo de medidas de ahorro y mejora de la eficiencia energética (15).

\section{Notas diferenciadoras respecto del modelo tradicional de suministro eléctrico}

Para que la electricidad llegue a las zonas donde es demandada es necesario que acontezca un complejo proceso del que son partícipes distintos agentes del mercado. El modelo tradicional de suministro parte de grandes instalaciones de generación de electricidad conectadas, por medio de redes eléctricas, a los centros de consumo identificados por todo el territorio (16).

Por su parte, nace un nuevo paradigma energético que aproxima las plantas de producción a las zonas de consumo, el denominado modelo de Generación Distribuida; siendo su ramificación más habitual la del autoconsumo, esto es, la forma de producción en la que el consumidor genera su propia electricidad en su red interior.

(14) BOE núm. 310, de 27 de diciembre.

(15) ORTIZ GARCÍA, Mercedes, «EI marco jurídico de la generación distribuida de energía eléctrica: autoconsumo, redes inteligentes y el derecho al sol", en Eficiencia energética y derecho/,Fernando García Rubio (dir.), Lorenzo Mellado Ruiz (dir.), Ed. Dykinson, S.L., Madrid, 2013, págs. 254-255.

(16) AGÚNDEZ BETELU, Miguel Ángel y MARTíNEZ SIMANCAS, Julián, en Energía eléctrica. Manual Básico para juristas, Editorial La Ley, 2014, págs. 20-32. 
De esta forma, se abre camino un nuevo modelo de generación que progresivamente va a ir integrándose en la red como un elemento de producción, eficiencia y gestión, y no como una mera conexión necesaria para obtener electricidad (17).

Así pues, como vemos INFRA, el autoconsumo, como forma de generación distribuida, presenta ventajas en diversos ámbitos con respecto al modelo tradicional de suministro eléctrico.

- Generación. Las instalaciones de producción emplean distintas fuentes de energía primaria para obtener electricidad a través de diversos mecanismos y procesos que, por lo general, son muy costosos. Éstas revisten un gran tamaño para así garantizar las necesidades de consumo futuras, por lo que es preceptiva la adopción de complejos proyectos de construcción a largo plazo.

Por su parte, las tecnologías empleadas para el autoconsumo presentan un carácter modular, de manera que el coste de generación va a descender progresivamente con la construcción masiva de instalaciones de autoconsumo (como por ejemplo las placas fotovoltaicas). Asimismo, se dan otros factores que aconsejan la implementación de tecnologías de autoconsumo: su tamaño reducido, que no hace necesarios grandes espacios para su instalación; su breve proceso de construcción o instalación, lo que disminuye las necesidades de predicción de demanda futuras que permiten calcular de forma anticipada las instalaciones que es necesario construir; la estandarización de sus componentes y de los permisos de instalación; y las facilidades de interconexión (18).

- Transporte. La electricidad se transporta por medio de la Red de Transporte, la cual se encarga de unir las plantas de generación con las zonas de consumo. La energía llegará a los centros de transformación próximos a las zonas de consumo y, a continuación, las redes de distribución se encargarán de llevarla hasta los puntos específicos donde se demanda (fábricas, viviendas u oficinas) (19). Con frecuencia nos encontramos con un transporte de electricidad a largas distancias, lo que lleva aparejado que parte de la energía se pierda en el proceso por culpa del calentamiento; algo que dependerá de factores como la extensión de

(17) LEIVA LÓPEZ, Alejandro D., "Balance neto energético. Estado de la cuestión en EE.UU», en Revista Aragonesa de Administración Pública, núm. 49-50, 2017, pág.344

(18) ANDREU CASADEMONT, Frederic, "Autoconsumo instantáneo: ¿Qué proyectos de autoconsumo solar son rentables para las empresas?», en Era solar: Energías renovables, vol.32, núm. 183, 2014, págs. 6-9.

(19) AGÚNDEZ BETELU, Miguel Ángel y MARTíNEZ SIMANCAS, Julián, en Energía eléctrica..., op. cit., págs. 2-10. 
red, la ubicación de las plantas de generación y de la demanda, la operación de la red y las características técnicas de los distintos equipos necesarios. En este sentido, el autoconsumo, al aproximar la producción a la zona de consumo, va a reducir de forma significativa las pérdidas de energía en la red.

Además, este tránsito de energía a través de redes responde a sus propios postulados físicos y son complejos de gestionar; lo que va a requerir de una actuación precisa y diligente por parte de los gestores de red, quienes deberán examinar la incidencia de las pequeñas instalaciones de autoconsumo sobre la operación de la red a la que están conectados e implementar medidas dirigidas al fomento de éstas. El autoconsumo impone nuevos retos sobre la gestión de la red que, previsiblemente, no serán tan complejos desde el punto de vista técnico.

Así, la generalización del autoconsumo implica una obligación de revisión del sistema de planificación y gestión de las redes de transporte y distribución de electricidad; lo que supone una reducción de la necesidad de refuerzo de éstas.

- Prestación del servicio(20). Los gestores de la red deben velar por la prestación de un suministro eléctrico seguro, eficiente y sostenible. Sin embargo, el modelo tradicional presenta deficiencias en materia de calidad y seguridad de suministro (véase las dificultades de acceso a la energía que se producen en zonas poco desarrolladas y alejadas de los centros de producción).

Así, optar por un modelo basado en el autoconsumo puede ayudar a enfrentar situaciones de incremento progresivo de la demanda energética en zonas donde la red de distribución es restringida; evitando así eventuales procesos de construcción muy dilatados y costosos que son necesarios para hacer frente a las restricciones de la red de distribución y garantizando que la energía llegue a un mayor número de usuarios.

Asimismo, el autoconsumo podrá utilizarse como reserva para reducir la alta carga que soporta la red en horas punta. Nos encontramos con pequeños generadores (véase una instalación fotovoltaica) que ofrecen una sólida fiabilidad y que, caso de fallar, podrán recibir apoyo de otras instalaciones que comparten su carga. Todo ello contribuye a una mejora de la calidad de servicio y de la fiabilidad del suministro.

- Medioambiente. El modelo productivo y energético tradicional perjudica gravemente al medio ambiente, lo que se acentúa aún más si ob-

(20) GONZÁLEZ RíOS, Isabel, "La incipiente regulación del autoconsumo de energía eléctrica: implicaciones energéticas, ambientales y urbanísticas", en Revista Vasca de Administración Pública, núm. 99, 2014, págs. 1623-1649. 
servamos las consecuencias severas del cambio climático. Los recursos fósiles disminuyen y la energía nuclear, además de presentar la desventaja de la radioactividad, no ofrece condiciones óptimas de seguridad de suministro(21). Por suerte, las energías renovables nacen para superar este desolador escenario ecológico, como consecuencia de un modelo productivo basado en fuentes finitas, y procurar así un mayor desarrollo sostenible. Es por ello que el autoconsumo nace para asumir el máximo protagonismo en la lucha contra el cambio climático y para, en consecuencia, preservar los principios medioambientales definidos en la normativa nacional, comunitaria e internacional. Se trata de un nuevo modelo que utiliza fuentes de energía renovable locales (aunque también cabe que sean utilizadas otras, menos contaminantes que las tradicionales, como el gas natural) y que está basado en la diversificación de recursos y el aumento de la autosuficiencia en las distintas zonas de consumo(22).

\section{Modalidades de autoconsumo}

El ya citado artículo nueve de la LSE se refiere a la figura del autoconsumo como "el consumo de energía eléctrica proveniente de instalaciones de generación conectadas en el interior de una red de un consumidor o a través de una línea directa de energía eléctrica asociada a un consumidor". Esta definición legal establece como idea principal la necesidad de que la electricidad consumida tenga origen en una instalación de generación que esté conectada de forma directa, a través de red interior o de una línea directa, al consumidor (como, por ejemplo, una placa solar ubicada en el tejado de una vivienda y conectada a los aparatos de consumo de ésta - electrodomésticos, vitrocerámica, calentador, etc. -) (23). Vemos así que esta figura descarta por completo que la energía provenga de la red de distribución, como sucede en el modelo tradicional de suministro.

Cabe significar que el tratamiento de la figura del autoconsumo estaba inmerso en una dispersión normativa en materia de electricidad. Y es a partir de la aprobación del RD 900/2015 cuando se establecen las condi-

(21) ALENZA GARCÍA, José Francisco, La regulación de las energías renovables ante el cambio climático, Ed. Aranzadi, 2014, págs. 157-160.

(22) GOICOECHEA, Félix, "Renovables y autoconsumo, el Titánic español», en Electra, núm. 184, 2014, págs. 14-16.

(23) Existiendo tantas redes internas o líneas directas como instalaciones de generación, por lo que, a diferencia de lo que ocurre con el modelo tradicional de suministro, no será necesaria una separación patrimonial de actividades; al menos en lo referido a estas micro redes. Vid. GONZÁLEZ RíOS, Isabel, "La incipiente regulación...», op. cit., págs. 1628-1629. 
ciones administrativas, técnicas y económicas para las distintas modalidades de autoconsumo de energía eléctrica.

Así, vemos en adelante cómo resulta esencial observar las especificidades de cada modalidad de autoconsumo para identificar, en consecuencia, el régimen jurídico-económico y administrativo aplicable a cada caso.

\subsection{Autoconsumo aislado}

De conformidad con lo dispuesto en el artículo 2.2 RD 900/2015, podemos afirmar de forma inequívoca que estarán exentos de cualquier cargo o peaje contenido en el citado reglamento, "[...] las instalaciones aisladas y los grupos de generación utilizados exclusivamente en caso de una interrupción de alimentación de energía eléctrica de la red eléctrica $[\ldots]$ ».

El precepto se refiere a aquellos usuarios que deciden prescindir de la red, esto es, una modalidad de autoconsumo, tipo 0 si se quiere, que quedaría excluida del ámbito de aplicación del reglamento. También serán definidas, según lo dispuesto en el artículo 3.1 j) como «[...] aquellas en las que no existe en ningún momento capacidad física de conexión eléctrica con la red de transporte o distribución ni directa ni indirectamente a través de una instalación propia o ajena [...]".

Sin embargo, en la práctica es muy complicado que el autoconsumidor opte por desconectarse, ya que la fuente de energía que necesita suele ser intermitente (por ejemplo, la radiación solar) y ello conduce a que tenga que dimensionar con mucha precisión su instalación y prever aquellos momentos en que la fuente de energía no juega a su favor (por ej. sol y viento).

En definitiva, el autoconsumidor que no está conectado a la red no paga nada, de manera que, como dispone la reciente Sentencia del Tribunal Supremo de 13 de octubre de $2017(24)$, "[...] No hay por tanto, y frente a la expresión que ha hecho fortuna, «impuesto al sol» propiamente tal, sino contribución a los costes del sistema cuando un autoconsumidor, además de consumir energía generada por él mismo, dispone del respaldo del sistema eléctrico para consumir electricidad del sistema en cualquier momento que lo necesite y, en su caso - como es lo habitual-, la consume efectivamente».

(24) STS (Sala de lo Contencioso-Administrativo, Sección $3 .^{a}$ ) núm. 1542/2017, de 13 de octubre, en contestación al recurso contencioso-administrativo ordinario número 1/4261/2015 interpuesto por la Asociación Nacional de Productores e Inversores de Energías Renovables (ANPIER). 


\subsection{El SUMINISTRO CON AUtOCONSUMO (TIPO 1)}

Es también conocido como autoconsumo instantáneo, ya que la electricidad generada va directamente a los aparatos de consumo, esto es, se consume de forma instantánea en el mismo momento en que se produce (en una mañana soleada un panel fotovoltaico funciona a pleno rendimiento y proporciona electricidad a los aparatos de consumo que están siendo utilizados en ese momento).

El artículo 4.1 a) RD 900/2015 dispone que para esta modalidad tipo 1 "[...] existirá un único sujeto de los previstos en el artículo 6 de la Ley 24/2013, de 26 de diciembre, del Sector Eléctrico, que será el sujeto consumidor [...]». Por tanto, debemos entender que el titular de la instalación de producción no puede considerarse "productor de energía eléctrica» en el sentido definido en el artículo 6 LSE (referido a los «sujetos que desarrollan actividades destinadas al suministro de energía eléctrica»); y, por ello, tampoco cabe afirmar que sean «instalaciones de producción». Al no existir interacción con la red, ya que no vierte energía a la red, no cabe considerarlo productor y, por tanto, no le serán exigibles determinadas obligaciones de carácter económico.

Sin embargo, sí estará sujeto a condiciones administrativas y técnicas derivadas de la conexión del centro de producción a la red y definidas en la normativa del sector eléctrico y reglamentaria sobre calidad y seguridad industrial, y, específicamente, las contenidas en el Real Decreto 1699/2011, de 18 de noviembre(25).

Además, la Memoria de Impacto Normativo del reglamento de autoconsumo pone de manifiesto que la pretensión del consumidor es la de conectar instalaciones de generación muy pequeñas sin vertido de energía sobrante, por lo que se prevé para ellas un régimen administrativo sencillo.

Sobre los requisitos (definidos en los artículos 4.1.a) y 5.1 RD 900/2015) que deben cumplir los usuarios para acogerse a la figura de autoconsumo tipo 1, encontramos: i) el consumidor debe ser titular de un punto de suministro, con una potencia contratada no superior a 100 $\mathrm{kW}$. En este punto, el legislador ha querido excluir a las instalaciones de potencia mayor por considerarlas, entendemos, de tamaño excesivo para el autoconsumo instantáneo. Lo que parece no armonizar con el tenor literal del artículo 2.2 RD 1699/2011, el cual define como "pequeñas» a aquellas instalaciones de hasta $1.000 \mathrm{~kW}$ que utilicen tecnologías como biomasa, biogás, cogeneración y biolíquidos. Es por ello que no

(25) Así lo establece el artículo 5.1.d) RD 900/2015, disponiendo que, a estos efectos de cumplir con las obligaciones de carácter administrativo y técnico, «[...] las instalaciones de generación de la modalidad de autoconsumo tipo 1 se considerarán instalaciones de producción». 
se entiende que las instalaciones de autoconsumo de más $100 \mathrm{~kW}$ que utilicen estas tecnologías queden excluidos por razón de tamaño, mientras, paralelamente, están dentro del ámbito de aplicación de la normativa reglamentaria sobre instalaciones de pequeña potencia; ii) El consumidor será titular de todos los equipos de consumo y, a su vez, de todas las instalaciones de generación conectadas a su red; iii) Las instalaciones de generación estarán ubicadas en la red interior del consumidor; iv) La suma de potencias instaladas de generación será igual o inferior a la potencia contratada por el consumidor; $v$ ) La electricidad generada debe ser destinada al consumo propio; vi) Las instalaciones de generación no pueden estar dadas de alta en el Registro de instalaciones de producción de energía eléctrica. Lo que evidencia la no consideración de éstas como «instalaciones de producción» y, por tanto, la no sujeción a las condiciones de carácter económico previstas para aquellas instalaciones que sí deben estar inscritas en el mencionado registro y que podrán vender su energía sobrante en el mercado mayorista o a través de contratos bilaterales (26).

\subsection{LA PRODUCCIÓN CON AUTOCONSUMO (TIPO 2)}

En esta modalidad tipo 2, de conformidad con lo dispuesto en el artículo 4.1.b) "[...] existirán dos sujetos de los previstos en el artículo 6 LSE, el sujeto consumidor y el productor». Es por ello que debemos entender que existe un "productor de energía eléctrica" titular de «instalaciones de producción" y que, por tanto, debe estar sujeto a condiciones de carácter no solo administrativas y técnicas (27), sino también económicas. Así pues, los titulares de estas instalaciones podrán acudir al mercado o a contratos bilaterales para vender su energía excedentaria.

Acerca de los requisitos (contenidos en los artículos 4.1.b) y 3 y $5.2 \mathrm{RD}$ 900/2015) que deben cumplirse para la modalidad de autoconsumo tipo 2: i) No existe límite de potencia instalada máximo ni mínimo. Por ello, la norma no impide que instalaciones de menos de $100 \mathrm{~kW}$ se acojan a esta modalidad tipo 2, siempre que estén inscritas en el Registro de instala-

(26) Así lo dispone el artículo 168.1 RD 1955/2000: «La inscripción en este registro será condición necesaria para poder realizar ofertas de energía eléctrica al operador del mercado y suscribir contratos bilaterales físicos".

(27) Vid. lo dispuesto en el artículo 5.2.c) RD 900/2015: «Las instalaciones de producción acogidas a la modalidad de autoconsumo tupo 2 deberán cumplir los requisitos técnicos contenidos en la normativa del sector eléctrico y en la reglamentación de calidad y seguridad industrial que les resulte de aplicación, en particular el Real Decreto 1955/2011 [...]». Vemos, así, que estarán sujetos a las mismas condiciones técnicas exigidas para la modalidad tipo 1. 
ción de producción de energía eléctrica; ii) La suma de las potencias instaladas de las instalaciones de producción será igual o inferior a la potencia contratada por el consumidor; iii) La instalación de generación se conecta directamente a la red eléctrica interior del consumidor o a través de línea directa; iv) En caso de que existan varias instalaciones de producción, el titular de todas ellas deberá ser la misma persona física o jurídica, esto es, el productor. Así como en ningún caso el generador se podrá conectar a la red interior de varios consumidores(28). Lo que impide el denominado "autoconsumo compartido o vecinal»(29), es decir, que varios consumidores reciban su electricidad de un usuario que produzca en una zona próxima(30). Vemos en adelante, y en un apartado específico, las novedades jurisprudenciales en la materia; $v$ ) Las instalaciones de generación deben estar dadas de alta en el Registro de instalaciones de producción de energía eléctrica.

Por último, según lo establecido en el artículo 4.1.b) RD 1955/2015, en esta modalidad de autoconsumo tipo 2 la instalación de producción podrá estar conectada: i) directamente en su red interior, donde se encuentran los aparatos de consumo; o ii) mediante una línea directa que conecte con su red interior (son casos en los que el centro de producción - p.ej. una placa fotovoltaica - debe ubicarse fuera de la red interior del consumidor - p.ej. por razones de espacio-; siendo necesaria una línea directa que una la instalación de generación - que está fuera de su red interior - con los aparatos de consumo - que están dentro de su red interior - ).

Sobre esta última (línea directa), cabe significar que, paralelamente, la normativa del sector eléctrico no permite estar conectado a través de línea directa a los aparatos de consumos ubicados en su red interior $y$, a la vez, a la red de electricidad para la venta de energía excedentaria. De manera que optar por la venta de energía sobrante supone la pérdida de calificación como línea directa (31).

(28) Cuestión que se ve reforzada por el artículo 13.2 RD 1699/2011, el cual dispone que «El titular de la red interior habrá de ser el mismo para todos los equipos de consumo e instalaciones de generación que tuviera conectados en su red [...]".

(29) Sobre las ventajas de esta modalidad de autoconsumo, Vid. LARRAZA LÁZCOZ, Álvaro, "Autoconsumo compartido: por qué impulsarlo y cómo", en Revista de Obras Públicas: Órgano profesional de los ingenieros de caminos, canales y puertos, núm. 3584, 2017, págs. 56-65.

(30) Sin embargo, sí sería posible que un centro de producción suministre electricidad a la comunidad de vecinos en su conjunto, esto es, a aquellos aparatos de consumo en régimen de copropiedad (garaje, ascensor, iluminación de zona de portal y otras zonas comunes, etc).

(31) Vid. los arts. 42 LSE y 69.2 RD 1955/2000, de 1 de diciembre, por el que se regulan las actividades de transporte, distribución, comercialización, suministro y procedimientos de autorización de instalaciones de energía eléctrica. Disponiendo que la instalación de producción conectada a la red quedará sometida a las condiciones de acceso de terceros a las redes, desvaneciéndose su consideración de línea directa. 


\section{Cuestiones de interés en un nuevo entorno social y tecnológico}

\subsection{LAS REDES INTELIGENTES Y EL ALMACENAMIENTO DE ENERGÍA}

En este nuevo entorno tecnológico resulta necesario el fortalecimiento de las denominadas redes inteligentes (en inglés, Smart grids) y una adecuada configuración de instrumentos dedicados al almacenamiento de energía.

El aumento de la densidad poblacional, asociado a la ágil urbanización acontecida en los últimos años (la ONU prevé que un $70 \%$ de la población viva en ciudades para 2030), plantea grandes retos a empresas, administraciones públicas e industrias. Las ciudades, para afrontar esta situación, se han dotado de grandes infraestructuras para ofrecer máxima cobertura al ciudadano, pero, sin embargo, esto se ha hecho de forma muy individualizada para cada uno de los elementos que componen la ciudad. Es por ello que no se han atendido las necesidades básicas de instituciones, empresas y de los propios habitantes en un plano económico, social y medioambiental; necesidades que, en definitiva, deben cubrirse en el marco de desarroIlo de las conocidas como ciudades inteligentes o eficientes. Así pues, este despliegue de infraestructuras y servicios, en respuesta a la coyuntura socioeconómica actual, resulta insuficiente para las grandes ciudades, por lo que deben afrontarse nuevos retos: lograr una sólida y alta eficiencia en el uso de sus recursos económicos y medioambientales y, paralelamente, garantizar el crecimiento económico en un marco adecuado de inclusión social. Por tanto, y para afrontar este escenario, es elemental el desarrollo tecnológico y regulativo del sector de la electricidad (32).

El sector eléctrico demanda estar cada vez más ligado a las tecnologías de la información inteligentes, de manera que todos los datos recopilados se envíen a través de una amplia variedad de redes inteligentes interconectadas que, a través de tecnologías de big data, los conviertan en comprensibles para los usuarios y les faciliten la toma de decisiones. La red inteligente presenta carácter bidireccional y tiene capacidad suficiente de adaptación a los cambios del sistema, ofreciendo información en tiempo real y satisfaciendo las necesidades energéticas de cada zona. Asimismo, deben facilitar la integración de las energías renovables para contribuir a la lucha contra el cambio climático y reducir las necesidades de creación de nueva infraestructura (33).

(32) RIVAS PEREDA, Carlos, "Autoconsumo y Smart Cities: Una introducción a tecnologías de futuro para la gestión eficiente de la energía", en $V$ Xornadas de Enxeñaría, Enerxía e Industria (XEEI): Eficiencia enerxética e innovación, Santiago de Compostela, 28 de xaneiro 2016 / BLANCO SILVA, Fernando y SARMIENTO DíEZ, Oriol (dir. Congreso), 2016, pág. 162.

(33) COLMENAR SANTOS, Antonio, BORGE DÍAZ, David, COLLADO FERNÁNDEZ, Eduardo y ALONSO CASTRO GIL, Manuel, en Generación distribuida, autoconsumo y redes inteligentes, Editorial UNED, Madrid, 2015, págs. 22-23. 
Específicamente, el autoconsumo es viable cuando el comportamiento y las acciones del prosumidor se integran sin obstáculos en la red a la que están conectados. Esto va a garantizar un sistema energético eficiente y sostenible donde las pérdidas de electricidad son mínimas y los niveles de calidad, eficiencia y seguridad de suministro son elevados.

Para alcanzar estas metas se ha avanzado hacia una mayor automatización, coordinación e integración de los usuarios con la red de transporte y distribución de electricidad. Así, se han adoptado medidas en materia de gestión de la demanda, mecanismos de control en tiempo real, ciberseguridad, fiabilidad del sistema y sistemas de predicción y cobertura (34). Así, es de esperar que, con el paso de los años, el avance ingenieril en materia de redes (también conocidas como micro redes) cristalice en un nuevo paradigma energético donde la generación distribuida y el autoconsumo reemplacen definitivamente a las formas tradicionales de suministro.

De otro lado, en materia de almacenamiento de energía, por todos es conocido que la energía eléctrica presenta la particularidad de tener que consumirse en el mismo momento en que se produce, esto es, que no puede ser almacenada en grandes cantidades. Si bien es cierto que en otros campos energéticos las dificultades de almacenamiento son menores (35).

Es por ello que las distintas modalidades de autoconsumo, y especialmente la aislada, están seriamente condicionadas por el avance tecnológico en materia de almacenamiento de electricidad.

El sector eléctrico está evolucionando hacia un nuevo modelo caracterizado por una mayor presencia de energías renovables, más limpias pero a su vez más complejas de gestionar que las convencionales por su carácter intermitente (p.ej. variabilidad de la energía solar y eólica), y que requiere mejoras en materia de eficiencia y flexibilización del sistema. Así, la energía verde se convierte en la más difícil de manejar, sobre todo porque la demanda eléctrica suele no coincidir con sus ciclos de producción (p.ej. existe una alta demanda energética por la noche, momento en que los paneles fotovoltaicos no producen nada). Es por ello que debemos plantearnos cómo gestionar de forma más eficiente y fiable la energía que producimos (36); siendo una de las claves los sistemas de alma-

(34) BONET SÁNCHEZ, Eduardo, "Transporte inteligente y ciudades digitales», en Política exterior, núm. 164, 2015, págs. 166-175.

(35) Sobre sistemas de almacenamiento energético en redes de generación distribuida, Vid. COLMENAR SANTOS, Antonio, BORGE DÍAZ, David, COLLADO FERNÁNDEZ, Eduardo y ALONSO CASTRO GIL, Manuel, en Generación distribuida..., op. cit., págs. 60-71.

(36) BRAFF, William A., MUELLER, Joshua M. y TRANCIK, Jessika E., "Value of storage technolgies for wind and solar energy", en Nature Climate Change, núm. 6, 2016, págs. 964-969. 
cenamiento de electricidad, donde destacan los avances en materia de almacenamiento doméstico de electricidad con cargo a baterías (37).

En definitiva, para avanzar hacia un sistema eléctrico más sostenible basado en la generación descentralizada de electricidad, y especialmente en el autoconsumo, es necesario que el prosumidor disponga de los medios (redes inteligentes bien desarrolladas y sólidos sistemas de almacenamiento) y garantías suficientes que le permitan llegar al punto de paridad de red favorable para afrontar las cuantiosas inversiones que requiere una instalación de autoconsumo. Todo ello impone grandes retos al gestor público o ente regulador, sobre el que recae la responsabilidad de desarrollar una política energética que facilite la penetración de estos sistemas de autoconsumo y contribuya a la mitigación de los efectos perniciosos del cambio climático. Como vemos en adelante, el legislador debe procurar un equilibrio entre, de un lado, la necesidad de introducir formas de producción descentralizada como el autoconsumo y, de otro, la de sufragar los costes asociados al sistema eléctrico.

\subsection{El DEBER DE MANTENIMIENTO DE LOS COSTES FIJOS DEL SISTEMA POR PARTE DEL AUTOCONSUMIDOR. A PROPÓSITO DE LA SOBRECAPACIDAD}

Son innumerables las ventajas que obtiene el autoconsumidor por estar conectado a la red eléctrica, a pesar de que su dependencia es menor que la de un usuario normal por tener su propio sistema de autoabastecimiento. Es por ello que aunque parece aceptado de forma generalizada que los costes empleados en el mantenimiento de la red deben ser sufragados por todos aquellos usuarios que estén conectados(38), incluido el autoconsumidor, y de forma proporcional al grado de interacción que

(37) La compañía norteamericana Tesla está ofreciendo al autoconsumidor doméstico un sistema de almacenaje electroquímico de la electricidad, esto es, una batería de ion-litio (Ilamada Powerwall) que amortigua los picos de consumo. Permite guardar la energía sobrante cuando la producción supera las necesidades de consumo (en las horas valle de un sistema de producción fotovoltaico, p.ej. cuando, durante el día, todos los miembros del hogar están fuera trabajando, en la escuela, etc, mientras que la placa solar produce a pleno rendimiento) y coger cuando la demanda sea mayor a la producción (p.ej. por la noche). Esta batería también podrá utilizarse para almacenar energía cuando las tarifas de electricidad son bajas, de manera que ello permitirá ahorrar en la factura cuando ésta se necesite en horas de demanda máxima y, obviamente, de mayor tarifa. Todo ello contribuye al aumento de la eficiencia de los sistemas de autoconsumo y favorece, sobre todo, a aquel que permanece aislado y que depende de lo que produce, ya que no está conectado a la red como respaldo. Vid. CHEVALIER, Michael, "¿Revolucionará...», op. cit., págs. 24-25.

(38) De conformidad con lo dispuesto en el artículo 9.3 LSE: «Todos los consumidores sujetos a cualquier modalidad de autoconsumo tendrán la obligación de contribuir a la financiación de los costes y servicios del sistema por la energía autoconsumida, cuando la instalación de generación o de consumo esté conectada total o parcialmente al sistema eléctrico (...) en los mismos términos que un consumidor no sujeto a ninguna de las modalidades de autoconsumo". Lo que nos permite observar cómo el autoconsumidor aislado no tiene la obligación de asumir ningún coste. 
tengan con ésta (39), todavía hay quien duda acerca de si el autoconsumidor debe pagar por el respaldo que le ofrece la red en condiciones de igualdad con respecto al resto de usuarios. Así pues, este epígrafe trata de reforzar la postura mayoritaria acerca de la necesidad de que todos los usuarios contribuyan al mantenimiento de los costes del sistema en condiciones de igualdad y no discriminación.

Las actividades económicas de red (donde localizamos las que integran el mercado eléctrico) presentan ciertas peculiaridades. La mayor parte de los servicios públicos (siendo el suministro de electricidad uno de ellos) están de forma directa o indirecta ligados a redes físicas o infraestructuras sobre las que descansan (véanse las redes de electricidad, de telecomunicación, de autopistas, de aguas, etc). Y es por ello que la doctrina de la regulación de este tipo de actividades, conocida como Regulación para la Competencia (40), va encaminada a garantizar unas condiciones de acceso objetivas y no discriminatorias, para lo que definen ciertos peajes de acceso que los usuarios deben satisfacer. Así, nos referimos a infraestructuras cuyo adecuado mantenimiento va a revertir positivamente sobre las condiciones de calidad y seguridad de suministro que convierten la conexión a la red en un respaldo sólido y fiable para el autoconsumidor, quien en consecuencia deberá contribuir a su mantenimiento.

Sin embargo, el coste de mantenimiento de la red (que proviene de los peajes de acceso y cargos por otros servicios - pagos por capacidad y servicios de ajuste del sistema-) no es el único cargo asociado a los costes fijos del sistema(41), sino que aparecen otros conceptos fijos regulados (p.ej. los sobrecostes generados por el sistema de primas a productores de energía renovable) que se van a imputar a todos los consu-

(39) Vid. GONZÁLEZ RíOS, Isabel, "La incipiente...», op. cit., págs. 1645-1647.

(40) Concepto inspirado en la doctrina americana de las «essential facilities" o de los "recursos esenciales». Vid. a mayor abundamiento ARIÑO ORTIZ, Gaspar, DE LA CUÉTARA, Juan Miguel y DEL GUAYO CASTIELLA, Íñigo, «Teoría y práctica de las regulación para la competencia. Hacia un nuevo concepto de servicio público», en Regulación Económica. Lecturas Escogidas, Ed. Thomson , Madrid, 2012, pág.567. A propósito de esta doctrina de los recursos esenciales, que fue inicialmente desarrollada en el "Derecho Antitrust" y que proyecta la idea del libre acceso a las redes para instrumentar ciertas competencias en los sectores regulados, que inspira el modelo actual de Regulación para la Competencia. Los autores se refieren a este concepto como aquel instrumento que crea competencia en ciertas actividades dentro de un sector (como las de red en el sector eléctrico) donde no existe competencia por ser consideradas monopolios naturales.

(41) Sobre los costes fijos del sistema Vid. Ias cifras ofrecidas por el Subdirector de Energía Eléctrica de la CNMC (Santiago Muñoz) en las Jornadas sobre Generación Distribuida y Autoconsumo que organizó el Club Español de la Energía (ENERCLUB) en febrero de 2016. El ponente destaca que dentro de los costes fijos del sistema, que representan aproximadamente el $40 \%$ del coste total de la factura, encontramos que un $22 \%$ se cubre con cargo a ingresos externos y un $78 \%$ a través de peajes de acceso a la red regulados y de otros cargos que, en consecuencia, no dependen del consumo energético. Por su parte, el 60 \% restante sí dependerá del consumo y representa la parte liberalizada de la factura. 
midores a través de la factura y que aparecen como consecuencia de las decisiones, más o menos acertadas, del regulador.

Por otro lado, la planificación sobre capacidad de producción en un mercado como el eléctrico no es una tarea sencilla. El desarrollo de capacidad de generación eléctrica que se necesita para responder a la demanda prevista está condicionado por muy diversos factores. Así, encontramos los acuerdos institucionales de carácter internacional, las especificidades técnicas del propio sistema eléctrico, el nivel de desarrollo de las infraestructuras de transporte e interconexiones internacionales, la transformación de las condiciones del mercado financiero y de materias primas, la estructura empresarial que integra el mercado de la electricidad, la dependencia energética, las preferencias sociales y, en general, la propia conformación del sistema en el modelo presente (42).

En este campo, si hay algo que diferencia a España del resto de países de la OCDE es la enorme sobrecapacidad instalada. El precedente demuestra que la regulación ha incentivado la creación de una capacidad excedentaria (23.000 MW de ciclo combinado y $25.000 \mathrm{MW}$ de renovables) que, tras no haber sido demandada, ha generado grandes costes para el sistema que se han visto reflejados en la factura eléctrica.

$Y$ es en este contexto donde debemos entender que el autoconsumidor que vierte su electricidad sobrante a la red está generando aún más sobrecapacidad, por lo que debe contribuir a los costes y sostenibilidad económica del sistema. Caso de no hacerlo, entendemos que el resto de consumidores que no generan su propia electricidad pagarían no solo por la parte de coste de red que deja de pagar el autoconsumidor, sino también por ese exceso de capacidad que el autoconsumidor introduce en la red en un momento en el que, con ocasión de la actual coyuntura económica, existe contracción de la demanda.

Asimismo, el autoconsumo genera un nuevo coste que tendrá que ver más con la transformación del modelo energético, esto es, más vinculado a tecnologías de la información protagonistas en el sistema de distribución y que generan grandes costes destinados a cubrir avances en software y hardware necesarios para la adecuada implementación de las redes inteligentes, así como para cubrir las distintas funciones de operación y mantenimiento que demanda el sistema de autoconsumo.

Por estos motivos, queda aún más justificado, si cabe, la necesidad contenida en la LSE de que el autoconsumidor contribuya al mantenimiento de los costes y servicios del sistema pagando los mismos cargos y peajes que un consumidor común no sujeto a ninguna de las modalida-

(42) BECKER ZUAZUA, Fernando, "Prospectiva de la electricidad en España», en Estudios de economía aplicada, núm. 2 (ejemplar dedicado a: El sector de la energía eléctrica en España), 2011, págs. $421-430$. 
des de autoconsumo(43). Si bien en este punto hay que destacar que algunos sectores se han pronunciado, haciendo lectura de las disposiciones contenidas en el RD 900/2015, acerca de la inexistencia de tal equidad en la contribución a los costes del sistema por parte del autoconsumidor a la que se refiere la LSE; siendo esta posición rechazada por la más reciente jurisprudencia delTribunal Supremo (44).

Sin embargo, entendemos que lo que sí debe someterse a debate es la metodología empleada para el cálculo de los peajes y otros conceptos incluidos en la factura (donde incluso se toman en cuenta los kW que produce el autoconsumidor), los cuales podrán no estar adecuadamente configurados desde el punto de vista regulativo(45). Por lo que esta última cuestión es la que debe abordarse diligentemente por el regulador para favorecer una integración natural y una evolución filosófica en un verdadero mercado interior de la electricidad.

\subsection{EL AUGE DE LA INDUSTRIA FOTOVOLTAICA Y LA NECESIDAD DE QUE EL AUTOCONSUMIDOR ESTÉ CONECTADO A LA RED}

En primer lugar, cabe afirmar que el autoconsumo no se vincula exclusivamente al uso de fuentes de energía renovable, ya que existen otras formas de autoconsumir a través de combustibles fósiles y otras fuentes convencionales (p.ej. gas natural, cogeneración, motores de combustión interna, entre otras). Sin embargo, las renovables han entrado en este campo con más fuerza.

(43) Vid artículo 9.3 LSE, el cual dispone que todos los autoconsumidores «[...] estarán obligados a pagar los mismos peajes de acceso a las redes, cargos asociados a los costes del sistema y costes para la provisión de los servicios de respaldo del sistema que correspondan a un consumidor no sujeto a ninguna de las modalidades de autoconsumo descrita [...]».

(44) Véase STS (Sala de lo Contencioso-Administrativo, Sección 3. ${ }^{a}$ ) núm. 1542/2017, de 13 de octubre. El recurrente (la asociación ANPIER) alega que los preceptos 17 y 18 RD 900/2015, en la medida en que definen un cargo variable transitorio por energía consumida y otro fijo por la potencia instalada, conducen al autoconsumidor a pagar más que los restantes sujetos no acogidos a ninguna de las modalidades de autoconsumo definidas. A lo que el Tribunal Supremo contesta disponiendo que "[...] no tiene razón la recurrente cuando afirma que se imponen a los autoconsumidores cargos que no pagan los consumidores ordinarios [...] En efecto, no puede calificarse así el hecho de que la metodología básica aprobada por el Gobierno en dichos preceptos tenga en cuenta como uno de los factores de cálculo el total de la energía consumida, incluida por tanto la energía autoconsumida que, como resulta evidente, es un elemento que solo existe en los usuarios autoconsumidores. El criterio empleado por el Real Decreto impugnado puede resultar objetable para la Asociación recurrente, pero no supone infracción alguna de la previsión legal del artículo 9 de la Ley del Sector Eléctrico, pues no es cierto que el autoconsumo pague más cargos o peajes que el consumidor ordinario»"

(45) DEL GUAYO CASTIELLA, Íñigo, DOMINGO LÓPEZ, Enrique y LEIVA LÓPEZ, Alejandro D., «Régimen jurídico...", op. cit., págs. 130-141. 
Específicamente, la tecnología fotovoltaica ha experimentado una intensa bajada de precios y, por ello, nos encontramos en un punto en que técnicamente es más barato autoproducir electricidad que comprarla a la compañía eléctrica, esto es, se produce la denominada paridad de red (en inglés, grid-parity(46)).

La energía fotovoltaica se caracteriza por ser versátil, ya que puede aprovecharse en plantas de gran tamaño (p.ej. huertos solares), medianas o pequeñas (p.ej. las placas fotovoltaicas instaladas en tejados de vivienda) y de tamaño muy pequeño (p.ej. pequeñas placas que abastecen a las cabinas de pago de la ORA). Incluso, en ocasiones, es la única tecnología viable para autoconsumir (p.ej. en estaciones espaciales).

Además de estas ventajas, cabe recordar los avances acontecidos en materia de almacenamiento de electricidad en instalaciones fotovoltaicas, destinados principalmente al sector residencial y a la pequeña empresa. En este campo los precios son cada vez más competitivos. Así, los consumidores deben valorar las opciones de autoconsumo y almacenamiento de electricidad como una solución integrada, considerando incluso la conveniencia de salir de la red. El regulador, por su parte, debe evaluar el papel que juega el almacenamiento a la hora de sufragar las necesidades de los sistemas y reflexionar acerca de qué cambios regulativos son necesarios para que este novedoso modelo funcione de forma eficiente (47).

Sobre la necesidad de que el prosumidor esté conectado a la red, y en consecuencia deba contribuir a la financiación de los costes y servicios del sistema por la energía autoconsumida en el sentido detallado SUPRA, debemos decir que desde un punto de vista técnico es muy necesario por razones de calidad de suministro. La LSE, y específicamente el artículo 51, emplea la desafortunada denominación de "calidad del producto", para referirse a un componente de la calidad de suministro. Sin embargo, la electricidad, como producto, no tiene calidad; siendo más acertado decir que ésta reside en la red por la que fluye la carga eléctrica. Así pues, los aparatos eléctricos necesitan de esa seguridad y continuidad que ofrece la red, para lo que resulta esencial que su frecuencia, tensión y potencia estén siempre ahí como respaldo.

Además, la conexión a la red requiere del usuario suscribir un contrato de acceso, el cual incorpora una serie de garantías para éste. En este

(46) A mayor abundamiento Vid. COLMENAR SANTOS, Antonio, BORGE DÍAZ, David, COLLADO FERNÁNDEZ, Eduardo y ALONSO CASTRO GIL, Manuel, en Generación distribuida..., op. cit., págs. 263-268. El estudio sitúa a la fotovoltaica como la tecnología más favorable a efectos de paridad de red, para lo que se examinan variables como el recurso renovable existente, la modularidad, la robustez y los costes de mantenimiento e inversión.

(47) SLAUGHTER, Andrew, "Almacenamiento de electricidad: tecnologías, impacto y perspectivas», en Cuadernos de energía, núm. 48, 2016, pág.64. 
contrato se definen obligaciones de gestión de red que prevén, ante su eventual incumplimiento por parte del propietario y gestor de la red, un régimen de responsabilidad administrativa (48) (con efecto sancionatorio) y contractual (49) (con efecto indemnizatorio).

Por tanto, desde el punto de vista tecnológico, el autoconsumidor que decida permanecer aislado deberá asumir numerosos riesgos de carácter técnico. Por ello entendemos que éste, con el nivel de desarrollo tecnológico actual, todavía necesita de la infraestructura de red si quiere obtener niveles óptimos de calidad y seguridad de suministro.

\section{Conflictos competenciales en materia de autoconsumo: Estado vs CCAA}

\section{Aspectos generales}

El régimen jurídico del autoconsumo eléctrico constituye una materia novedosa que es definida en el artículo 9 de la LSE y desarrollada por el RD 900/2015. Se trata de una fuente alternativa de producción de electricidad que necesitaba de la configuración de un marco legal y reglamentario específico. Como establece el preámbulo de la LSE, se persigue el desarrollo ordenado de la actividad de autoconsumo en armonía con la necesidad de garantizar la sostenibilidad técnica y económica del sistema eléctrico en su conjunto, para lo que se obliga a los titulares de instalaciones de autoconsumo a que contribuyan a la financiación de los costes y servicios del sistema en la misma cuantía que el resto de consumidores.

Para lograr estos fines, y de conformidad con lo dispuesto en el artículo 9 LSE, se atribuye al Estado competencia en las siguientes materias (que

\footnotetext{
(48) Vid. los capítulos II («Infracciones y sanciones») y III ("Procedimiento sancionador») del Título $\mathrm{X}$ de la Ley del Sector Eléctrico.

(49) Vid. BARCELÓ DOMÉNECH, Javier, "La incidencia de la fuerza mayor en el suministro de energía eléctrica: estudio de la cuestión en la jurisprudencia», en Práctica de Derecho de Daños, núm. 75, Sección de Estudios, 2009, págs. 6-17. El autor defiende que la calidad de suministro constituye una sólida obligación contractual para la empresa eléctrica -comercializadora o distribuidora-. En este sentido, el afectado por cualquier irregularidad de que adolezca el suministro eléctrico tiene derecho a exigir, en base al clausulado contractual, los daños y perjuicios causados por el incumplimiento del deber de velar por la seguridad y calidad de suministro (p.ej. daños que ocasionan apagones u oscilaciones de tensión sobre aparatos electrónicos y maquinaria empleada en distintos sectores). Asimismo, el autor se refiere al deber de la compañía eléctrica, dependiendo del emplazamiento geográfico en el que se encuentre, de prever los efectos nocivos de cierta fenomenología meteorológica, debiendo ser diligente en la adopción de medidas precautorias dirigidas a que estas circunstancias sobrevenidas no afecten a la adecuada prestación del servicio de suministro eléctrico: exceptuando casos en que se produce fuerza mayor, esto es, cuando se dan fenómenos de una envergadura extraordinaria.
} 
van a ser definidas reglamentariamente): concepto y modalidades de autoconsumo; obligaciones y derechos que derivan de la conexión a la red; procedimiento de inscripción obligatoria en el registro administrativo de autoconsumo y comunicación de datos; condiciones administrativas y técnicas para la conexión a la red; condiciones económicas para verter la energía no autoconsumida a la red; ámbito organizativo; así como aquellas disposiciones reglamentarias necesarias para el desarrollo y aplicación de la ley. Por su parte, el preámbulo del RD 900/2015 también refuerza la competencia estatal, disponiendo que las instalaciones de producción de pequeña escala destinadas al autoconsumo "[...] supondrán un reto adicional en cuanto a su integración en el sistema y la gestión de las redes [...]». Asimismo, deberán cumplir en todo el territorio nacional con unas condiciones administrativas, técnicas y económicas definidas para garantizar un desarrollo ordenado de las distintas formas de autoconsumo compatible con la sostenibilidad económica y técnica del sistema en su conjunto. Por todo ello, las disposiciones contenidas en el artículo 9 LSE y en el RD 900/2015 entrarían en la esfera de la ordenación básica de las actividades de suministro de energía eléctrica y del establecimiento de su régimen económico; cuya competencia se atribuye al Estado.

Siendo esto así, algunas Comunidades Autónomas han reclamado competencias en materia de autoconsumo atribuidas al Estado (50), esgrimiendo como argumento principal que la configuración de las condiciones técnicas, administrativas y económicas a que están sujetas las instalaciones de autoconsumo: i) no entran en el ámbito de la coordinación de la planificación general de la actividad económica de competencia estatal (art. 149.1.13 CE); ii) no presentan un régimen de autorizaciones cuya concesión competa al Estado, ya que el aprovechamiento de la instalación de autoconsumo no afecta a otra Comunidad Autónoma ni el transporte de energía sale de su ámbito territorial (art. 149.1.22 CE); iii) desbordan el marco de actuación básico en materia energética que compete al Estado (art. 149.1.25 CE); iv) corresponde a la Comunidad Autónoma en virtud de las competencias compartidas en materia de energía que los estatutos de autonomía reconocen (51).

(50) Vid. algunos de los recursos de inconstitucionalidad admitidos a trámite interpuestos contra el artículo 9 LSE: núm. 1820-2014 (BOE núm. 116, de 13 de mayo), interpuesto por el Parlamento de Cataluña; núm. 1908-2014 (BOE núm. 116, de 13 de mayo), interpuesto por el Gobierno de la Generalitat de Cataluña; y núm. 5819-2014 (BOE núm. 258, de 24 de octubre), interpuesto por el Consejo de Gobierno de la Junta de Andalucía.

Así como el conflicto positivo de competencias admitido a trámite núm. 574-2016 (BOE núm. 68, de 19 de marzo), interpuesto por el Gobierno de la Generalitat de Cataluña contra los artículos 1, 2, 4, 5, $6,7,8,19,20,21$ y 22 , las disposiciones adicionales primera, segunda y novena, así como la disposición final secta del RD 900/2015.

(51) Vid., p.ej., la atribución de competencias compartidas contenida en el artículo 133.1 del Estatuto de Cataluña en las siguientes submaterias: «a) La regulación de las actividades de producción, 
En este orden de cosas, y ante estas reclamaciones de competencia, el Tribunal Constitucional se ha pronunciado a favor de las atribuciones competenciales estatales contenidas en el artículo 9 LSE, disponiendo que "[...] dicha regulación persigue integrar este modo de producción y consumo de electricidad en el sistema eléctrico, así como prever el establecimiento por vía reglamentaria de un régimen económico de las distintas modalidades de autoconsumo, determinando la contribución de la energía autoconsumida a la cobertura de los costes y servicios del sistema eléctrico. Por un lado, define el régimen básico de la actividad de uno de los sujetos que interviene en el sistema eléctrico, definición que ha de responder a unas características homogéneas en un sistema que opera de forma única para todo el territorio nacional, $\mathrm{y}$, por otro, establece una serie de criterios generales respecto al régimen económico aplicable al mismo, extremos ambos que tienen por finalidad garantizar un desarrollo ordenado de la actividad compatible con la sostenibilidad económica y técnica del sistema en su conjunto, uno de los objetivos fundamentales de la Ley del Sector Eléctrico [...]» (52).

Asimismo, respecto del artículo 9 LSE, elTC ha concluido que «[...] Se trata, entonces, de una cuestión que se sitúa en el ámbito de la ordenación básica de las actividades de suministro de energía eléctrica y del establecimiento de su régimen económico, para lo que los títulos de los arts. 149.1 .13 y 25 CE proporcionan fundamento competencial adecuado $[\ldots] »(53)$.

En definitiva, el parecer general del TC se inclina a favor del Estado y refuerza, por tanto, su intervención en la ordenación del sector, tanto a través de un título general relativo a la planificación de la economía (art. 149.1.13 CE) como mediante uno más específico relativo al sector energético (art. 149.1.25 CE). Asimismo, también considera que el autoconsumo puede generar aprovechamiento fuera del ámbito territorial de la Comunidad Autónoma, por lo que tendrá cabida la intervención estatal por vía del artículo 149.1.22 CE. Sin embargo, como vemos en adelante, la

\footnotetext{
almacenaje y transporte de energía, el otorgamiento de las autorizaciones de las instalaciones que transcurran íntegramente por el territorio de Cataluña y el ejercicio de las actividades de inspección y control de todas las instalaciones existentes en Cataluña; b) La regulación de la actividad de distribución de energía que se lleve a cabo en Cataluña, el otorgamiento de las autorizaciones de las instalaciones correspondientes y el ejercicio de las actividades de inspección y control de todas las instalaciones existentes en Cataluña; c) El desarrollo de las normas complementarias de calidad de los servicios de suministro de energía; d) El fomento y la gestión de las energías renovables y de la eficiencia energética».
}

(52) STC 60/2016, de 17 de marzo (BOE núm. 97, de 22 de abril), Fundamento Jurídico 3, pág. 27507.

(53) Véase SSTC 72/2016, Fundamento Jurídico 3, pág. 33703 (BOE núm. 122, de 20 de mayo); 205/2016 (BOE núm. 7, de 9 de enero), Fundamento Jurídico 3, pág. 1198; y 60/2016, Fundamento Jurídico 3, pág. 27507. 
STC 68/2017 de 25 de mayo (54) pone fin a esta rigidez doctrinal y estima parcialmente (en lo relativo a la impugnación de la competencia estatal en materia de registro de autoconsumo y autoconsumo compartido) un conflicto positivo de competencias planteado por el Consejo de Gobierno de la Generalitat de Cataluña.

\section{Posición de las Comunidades Autónomas}

Desde la regulación del autoconsumo en la LSE (artículo 9) han venido aconteciendo controversias en relación a las competencias atribuidas al Estado.

Asimismo, como vemos INFRA, el desarrollo de esta figura a cargo del RD 900/2015 ha provocado que varias Comunidades Autónomas consideren invadidas sus competencias en materia de autoconsumo.

\subsection{Materias específicas objeto de CONFlicto (55)}

\subsubsection{Objeto y ámbito de aplicación}

Los artículos 1 y 2 delimitan el objeto y ámbito de aplicación del RD de autoconsumo y manifiestan su vocación de regulación de todas las instalaciones existentes. Así, esta delimitación implica sujetar a todas las instalaciones de autoconsumo a las condiciones administrativas, técnicas y económicas reguladas en subsiguientes preceptos, algunos de los cuales extralimitan el campo de actuación básico atribuido al Estado en materia de energía o, incluso, reservan funciones ejecutivas y aplicativas al Estado que corresponden a la Comunidad Autónoma.

Asimismo, las autonomías entienden que el artículo 9.2 (párrafo segundo) LSE no otorga habilitación legal al Gobierno de España para establecer una delimitación que se proyecte sobre todas las instalaciones existentes, ya que solo le habilita para que defina específicamente las condiciones económicas de las instalaciones de modalidad tipo 2 (producción con autoconsumo) que vendan al sistema la energía sobrante no autoconsumida y, por tanto, perciban retribución por ello; y no así las propias de las instalaciones que no perciben retribución (tipo 1).

(54) BOE núm. 156, de 1 de julio.

(55) Las cuestiones aquí tratadas son extraídas de las impugnaciones realizadas por varias Comunidades Autónomas contra el RD de autoconsumo. Vid., p.ej., el recurso contencioso-administrativo interpuesto por el Gobierno de Aragón (admisión a trámite publicada en BOE núm.298, de 14 de diciembre) y el conflicto de competencia núm. 574-2016 interpuesto por el Gobierno de Cataluña (admisión a trámite publicada en $B O E$ núm. 68 , de 19 de marzo). 


\subsubsection{Condiciones técnicas y administrativas para la modalidad tipo 1}

La aplicación conjunta de los artículos 4 y 5 define como modalidad tipo 1 (autoconsumo instantáneo) a aquellas instalaciones de generación de potencia inferior a $100 \mathrm{~kW}$, las cuales estarán sometidas a condiciones técnicas y administrativas definidas por el Estado.

En este punto, las CCAA entienden que dichas instalaciones de generación de pequeña escala y potencia, que se encuentran en un mismo espacio físico, no tienen una incidencia técnica o de gestión suficiente que justifique el carácter básico de la configuración de las condiciones administrativas y técnicas a que están sometidas; por lo que su desarrollo deben entrar en la esfera competencial autonómica.

Sin embargo, sí estaría justificado el carácter básico de las condiciones económicas en la modalidad tipo 2, para instalaciones de potencia mayor a $100 \mathrm{~kW}$.

\subsubsection{Potencia instalada}

Los artículos 5.1.b) y 5.2.a) establecen como requisito de carácter técnico para ambas modalidades de autoconsumo que la suma de las potencias instaladas de generación sea igual o inferior a la potencia contratada por el consumidor. Sin entrar en valoraciones acerca de si esta medida resulta eficiente o no, las autonomías entienden que se está otorgando un carácter básico, y por tanto de competencia estatal, a una materia inequívocamente de carácter técnico.

Además, son cuestiones que afectan de forma directa a la red de distribución, sobre cuya regulación se atribuye gran protagonismo a la Comunidad Autónoma. Por lo que todo ello puede suponer una vulneración del concepto formal y material de bases.

\subsubsection{Calidad del servicio}

En relación a la calidad del servicio, y específicamente en lo referido a incidencias provocadas por instalaciones de autoconsumo en la red de distribución, el artículo 6 hace una remisión a la LSE y, específicamente, a su artículo 51 LSE.

Sobre esta cuestión, cabe significar que las empresas distribuidoras no asumirán responsabilidad por las posibles incidencias en la calidad que puedan tener su origen en las propias instalaciones de autoconsumo. 
En cualquier caso, y sin entrar a valorar las disposiciones contenidas en los citados artículos, se trata de una materia que afecta a la red de distribución y, por tanto, que entra en la esfera competencial de la autonomía.

\subsubsection{Conexión a la red}

El artículo 7 obliga a todos los consumidores que quieran acogerse a cualquiera de las modalidades de autoconsumo a solicitar una nueva conexión a la red, incluso cuando no tienen intención de verter su energía excedentaria.

Al tratarse de una materia de carácter técnico, es la Comunidad Autónoma quien debe concretar las especificidades relativas a la conexión de una instalación de autoconsumo a la red de distribución, sin perjuicio del cumplimiento de aquellos criterios básicos definidos por el Estado.

Asimismo, el artículo 33.4 LSE aclara que ante discrepancias suscitadas en torno al otorgamiento o denegación del permiso de conexión a las redes de competencia autonómica (véase la conexión a redes de distribución), serán las propias Comunidades Autónomas las que deban pronunciarse sobre ello.

\subsubsection{Contratos de acceso e información}

El artículo 8 exige a los usuarios de cualquiera de las modalidades de autoconsumo la suscripción de un nuevo contrato de acceso con la empresa distribuidora o modificar el ya suscrito como cualquier otro consumidor. Esto incluye al autoconsumidor de la modalidad tipo 1 que no vierte energía a la red o que lo hace sin recibir retribución por ello.

Así, no cabe entender que la exigencia de formalización de un nuevo contrato esté dentro de las bases y coordinación de la planificación general de la actividad económica de competencia estatal; sino más bien, por existir afectación a la red de distribución, autonómica.

Por su parte, la DA 9. ${ }^{a}$ prevé que las empresas distribuidoras remitan a la Comisión Nacional de los Mercados y la Competencia (en adelante, CNMC) información sobre los contratos de acceso suscritos para cada modalidad de autoconsumo, facilitándose a su vez el acceso a tan solo al Estado (Dirección General de Política Energética y Minas). En este punto, las autonomías entienden que esta información debiera ser pues en conocimiento, en primer lugar, de la Comunidad Autónoma, pues se trata de una competencia ejecutiva sobre instalaciones de autoconsumo sitas en un territorio determinado. 


\subsubsection{Registro de instalaciones}

Los artículo 19 a 22 regulan el registro de autoconsumo de energía eléctrica, de conformidad con lo dispuesto en el artículo 9 LSE.

La regulación del registro para todas las modalidades de autoconsumo define detalladamente un procedimiento de inscripción y gestión que queda sin género de duda en manos del Estado (a través de la Dirección General de Política Energética y Minas).

Sin embargo, las autonomías consideran que, para la modalidad tipo 1, ello supone una injerencia en el ejercicio de funciones ejecutivas que les son atribuidas, ya que son instalaciones de escasa incidencia económica en el sistema con afectación a la red de distribución y, por ello, sin sujeción a condiciones de carácter económico que demandasen intervención estatal.

Por otro lado, sostienen que un registro centralizado de carácter estatal solo tendría justificación para la modalidad de autoconsumo tipo 2 y, más concretamente, en relación al control de la venta de electricidad al sistema y su correspondiente retribución, esto es, en su labor de centralización de datos; ya que se trata de una modalidad de autoconsumo con gran incidencia técnica y de gestión que justifica su sujeción a condiciones económicas de carácter básico y competencia del Estado.

Sin embargo, el control del proceso de inscripción y gestión (autorización, modificación y cancelación) representa facultades ejecutivas de inspección y control que exceden del ámbito de actuación del Estado (56).

En definitiva, se reclama que las funciones de centralización de datos, procedimiento y gestión del registro sean de competencia autonómica para la modalidad de autoconsumo tipo 1, mientras que para la modalidad tipo 2 solo lo serán las de procedimiento y gestión, y no tanto una labor de recopilación de datos que se admite que sea asumida por el Estado por su gran incidencia económica sobre el sector.

\subsubsection{Instalaciones de cogeneración}

La DA 1. a en su apartado 6 a), que regula las instalaciones de cogeneración asociadas al consumidor, reserva al Estado (y específicamente a la Di-

(56) Todo ello encuentra apoyo en la doctrina de la STC 223/2000, de 21 de septiembre (BOE núm. 251, de 19 de octubre). Se trata de un conflicto positivo (núm. 281/93) de competencia planteado por el Consejo Ejecutivo de la Generalitat de Cataluña respecto del Real Decreto 1085/1992, de 11 de septiembre, por el que aprueba el Reglamento de la actividad de distribución de gases licuados del petróleo. 
rección General de Política Energética y Minas) la función de autorizar una configuración de medida singular cuando se acredite la imposibilidad técnica o física para adaptar la configuración de medida a las condiciones generales.

Sin embargo, cabe matizar que, de conformidad con lo dispuesto en el artículo 149.1.22 CE, esta función de autorización solo debería ser atribuida al Estado cuando se trate de instalaciones de cogeneración de competencia estatal, esto es, cuando su aprovechamiento afecte a otra Comunidad Autónoma o el transporte salga de su ámbito territorial. Mientras que la función de autorización de medida singular para aqueIlas instalaciones que, por no suponer aprovechamiento a otra Comunidad, sean competencia de Comunidad Autónoma, será competencia de ésta.

\subsubsection{Autorización de vertido excedente}

El apartado primero de la DA 2. ${ }^{a}$ reserva al Estado (de nuevo a la Dirección General de Política Energética y Minas) la facultad de autorizar el vertido de electricidad a los consumidores conectados en alta tensión (modalidad tipo 2), cuando su producto secundario sea la producción de electricidad, que debido a la implantación de mecanismos de ahorro y eficiencia energética no pueda consumirla en su propia instalación.

En este punto, y siguiendo la línea argumental defendida SUPRA, cabe invocar el contenido del artículo 149.1.22 CE, en la medida en que esa competencia estatal debiera estar justificada solo para aquellas instalaciones cuyo sobrante de energía se proyecte fuera de la Comunidad Autónoma. Y, por el contrario, serán de competencia autonómica aquellas que no supongan aprovechamiento fuera de su territorio (que, por tratarse de energía excedentaria, entendemos que serán las más comunes).

\subsection{EN ESPECIAL: EL AUTOCONSUMO COMPARTIDO O VECINAL}

También las Comunidades Autónomas se han pronunciado acerca del carácter básico de la prohibición contenida en el artículo 4.3 RD 900/2015.

El precepto dispone que «En ningún caso un generador se podrá conectar a la red interior de varios consumidores", impidiendo que los autoconsumidores de un edificio dividido en propiedad horizontal u otra modalidad compleja o de un conjunto de casas adosadas compartan la línea 
de conexión de un generador a la red interior, esto es, impidiendo el denominado autoconsumo compartido o vecinal.

Entienden las autonomías que esta prohibición no reúne ninguno de los elementos que justifiquen el carácter básico o unitario de aplicación necesario en todo el territorio del Estado, y, por tanto, vulnera el contenido del artículo 149.1.25 CE.

Así pues, se estaría impidiendo a las Comunidades Autónomas optar por un modelo basado en el autoconsumo compartido que armonice con los objetivos medioambientales definidos por la Unión Europea para el año 2020 y con los artículos 6, 7 y 9 de la Directiva 2010/31/UE del Parlamento y del Consejo, de 19 de mayo, relativa a la eficiencia energética de los edificios (57).

Por lo general, cuando hablamos de autoconsumo pensamos en un único titular de la instalación de producción y, a su vez, de los aparatos de consumo. Sin embargo, son numerosas las ventajas económicas y sociales que el titular de la instalación de producción puede proporcionar a aquellos usuarios que no disponen de espacio suficiente para instalar, por ejemplo, paneles solares (58). El autoconsumo compartido es primordial para desarrollar el modelo de generación distribuida, ya que implica un grado de eficiencia mucho mayor que las tres categorías de autoconsumo previstas en el RD 900/2015.

Por ello, la comunidad científica se ha pronunciado de forma unánime acerca de la necesidad de una regulación coherente con el avance tecnológico y que no imponga trabas al desarrollo del autoconsumo (59).

De esta forma, el artículo 4.3 RD de Autoconsumo deja sin desarrollo, y vacío en la práctica, la categoría de autoconsumo definida en el artículo 9.1.d) LSE, el cual establece: "Cualquier otra modalidad de consumo de energía eléctrica proveniente de una instalación de generación de energía eléctrica asociada a un consumidor". Si bien es cierto que esta hermética formulación del RD 900/2015 ve su fin tras el reciente pronunciamiento delTC que analizamos a continuación.

(57) DOUE núm. 153, de 18 de junio.

(58) Vid. LARRAZA LÁZCOZ, ÁLVARO, "Autoconsumo compartido: ...», op. cit., pág.56.

(59) Véase ALBA RíOS, Juan José, ARAGONÉS AHNERT, Vanessa, BARQUÍN GIL, Julián y MOREDA DÍAZ, Eduardo, "La regulación del autoconsumo en España: ¿un impuesto al Sol?», en Revista de Obras Públicas: Órgano profesional de los ingenieros de caminos, canales y puertos, núm. 3584, 2017, págs. 40-47; FABRA UTRAY, Jorge, «El marco actual y potencial del sistema eléctrico español para la generación distribuida de electricidad", en Revista de Obras Públicas: Órgano profesional de los ingenieros de caminos, canales y puertos, núm. 3584, 2017, págs. 20-25; MENDOZA LOSANA, Ana Isabel, "Trabas al autoconsumo de energía eléctrica», en Aranzadi civil-mercantil. Revista doctrinal, núm 3, 2016, págs. 29-46. 


\section{Posición del Tribunal Constitucional. A propósito de la STC 68/2017}

La Sentencia delTC núm. 68/2017, de 25 de mayo(60), es la primera en pronunciarse a favor de la competencia autonómica sobre algunas de las materias relacionadas en el RD 900/2015. Es el resultado del conflicto positivo de competencia planteado por la Generalitat de Cataluña (61) contra varios artículos del RD de Autoconsumo.

Ante el conflicto planteado, el TC tuvo que determinar cuál es el título o títulos prevalentes a los efectos de dirimir este conflicto. Para lo cual, como dispone el Fundamento Jurídico 3 de la STC 236/2012, de 13 de diciembre (62), "cuando se ofrezcan por las partes en el proceso constitucional (en este caso, la Generalitat de Cataluña y el Estado) diversas calificaciones sustantivas de las disposiciones o actos en conflicto que pudieran llevar a identificaciones competenciales también distintas, ha de apreciarse, para llegar a una calificación competencial correcta, tanto el sentido o finalidad de los varios títulos competenciales y estatutarios, como el carácter, sentido y finalidad de las disposiciones traídas al conflicto, es decir, el contenido del precepto controvertido, delimitando así la regla competencial aplicable al caso».

La Generalitat impugnó varios de los preceptos del RD 900/2015 en el sentido ya abordado, siendo estas pretensiones estimadas parcialmente por elTC. Específicamente, se declara la inconstitucionalidad y nulidad de los artículos 4.3, 19, 20, 21 y 22 RD 900/2015.

\subsection{Sobre El Registro de AUtoconsumo}

Por lo que respecta a la impugnación de los artículo 19 a 22 del RD 900/2015, la Abogacía del Estado alude a la cobertura constitucional que ya le fue otorgada al Estado para el establecimiento de un registro único que abarque todas las modalidades de autoconsumo por SSTC 32/16 de 18 de febrero(63) y 60/16 de 17 de marzo. Aunque hay que recordar que en este caso fue una cobertura otorgada con ocasión de la impugnación del contenido general sobre registro estatal contenido en el artículo 9.4 LSE. Sin embargo, ahora corresponde examinar si el desarrollo del precepto citado con cargo a los artículo 19 a $22 \mathrm{RD}$ de Autoconsumo respeta

(60) BOE núm. 156, de 1 de julio.

(61) Conflicto de competencia núm. 574-2016 interpuesto por el Gobierno de Cataluña (admisión a trámite publicada en $B O E$ núm. 68, de 19 de marzo de 2016).

(62) $B O E$ núm. 10, de 11 de enero.

(63) BOE núm. 71, de 23 de marzo. 
la doctrina constitucional en materia de registros administrativos que, según las sentencias citadas, otorgó la competencia al Estado.

Así pues, el TC entiende que estos preceptos contenidos en el RD de Autoconsumo exceden el ámbito competencial del Estado al atribuir a este registro funciones de carácter ejecutivo que vulneran las competencias autonómicas. Ello se desprende del artículo 19.3, el cual dispone que «El Registro administrativo de autoconsumo de energía eléctrica tendrá como finalidad el control y adecuado seguimiento de los consumidores acogidos a cualquiera de las modalidades de autoconsumo de energía eléctrica». Se trata de una función de control y seguimiento que tendrá un fuerte componente ejecutivo y que, por tanto, corresponde regular a las Comunidades Autónomas. Solo tendría cabida que esta función ejecutiva fuese asumida por el Estado si la función que se atribuye al registro afectase a la homogeneidad técnica del sistema en su conjunto necesaria para su correcto funcionamiento. Sin embargo, el TC entiende que esta excepcionalidad no tiene lugar para las funciones atribuidas en el artículo 19.

Asimismo, el TC concluye que los artículos 20 a 22 del RD de Autoconsumo, que regulan la obligación de todos los consumidores acogidos a las modalidades de autoconsumo a solicitar la inscripción en el registro estatal (art. 20), el procedimiento de inscripción en el registro (art. 21) y la modificación y cancelación de las inscripciones (art. 22), son contrarios al orden constitucional de competencias. El Tribunal remite a su propia doctrina de las SSTC 243/1994, de 21 de julio(64) (Fundamento Jurídico 6) y 197/1996, de 28 de noviembre (65) (Fundamento Jurídico 12), en las cuales se dispone que la inscripción registral es un acto típicamente ejecutivo; de manera que para que esta inscripción en registros estatales sea compatible con las competencias ejecutivas de las CCAA, el Estado «[...] debe aceptar como vinculantes las propuestas de inscripción y de autorización o de cancelación y revocación que efectúen las Comunidades Autónomas que ostentan las competencias ejecutivas [...]».

\subsection{Sobre EL AUTOCONSUMO COMPARTIDO}

La Abogacía del Estado, en oposición a la impugnación formulada por la Abogada de la Generalitat de Cataluña, defiende a ultranza la legalidad de la prohibición contenida en el artículo 4.3 RD 900/2015. Esgrime como argumento que la prohibición reglamentaria es solo una concreción técnica de lo dispuesto en el artículo 39.3 LSE, el cual establece que todas las insta-

(64) BOE núm. 197, de 18 de agosto.

(65) BOE núm. 3, de 3 de enero. 
laciones destinadas a más de una consumidor tendrán la consideración de red de distribución y, en consecuencia, deberán ser cedidas a la empresa distribuidora de la zona y se convertirá en una infraestructura abierta al acceso de terceros a la red, por lo que no existirá una red interior.

En este punto, el TC no entiende como justificación la remisión al artículo 39.3 LSE. Y ello porque el artículo 4.3 RD de Autoconsumo "[...] parte de la existencia de redes interiores de varios consumidores cuya existencia niega la Abogacía del Estado en su argumentación. Nada permite excluir que la susodicha "red interior de varios consumidores» [...] se corresponda con lo que técnicamente se denominan «instalaciones de enlace», es decir, con aquellas que a través de la acometida unen la red de distribución con las instalaciones interiores o receptoras de cada uno de los usuarios que puedan encontrarse en un misma urbanización o edificio, y que discurren siempre por lugares de uso común pero que permanecen en propiedad de los usuarios, los cuales se responsabilizarán de su conservación y mantenimiento (conforme establece la instrucción técnica complementaria para baja tensión ITC-BT12 del Ministerio de Ciencia y Tecnología) [...]".

Por tanto, el TC no admite que las instalaciones destinadas a más de un consumidor sean consideradas red de distribución abierta al acceso de terceros, sino que se trata de instalaciones de enlace (acometidas) que discurren por lugares de uso común (donde hay red de distribución) pero que son propiedad del usuario particular. Por lo que decide anular el artículo 4.3 RD de Autoconsumo, en la medida en que impide que varios consumidores reciban energía en su red interior procedente de un mismo centro de producción.

Asimismo, y desde el punto de vista competencial, el TC no encuentra elementos que justifiquen el carácter básico de aplicación (66), por lo que se estaría impidiendo que las CCAA elijan un modelo energético basado en el autoconsumo compartido.

$\mathrm{Ni}$ en el preámbulo del Real Decreto, ni en la memoria de análisis de impacto normativo que se acompañó al proyecto, ni en la respuesta del

(66) EITC entiende que este caso del artículo 4.3 no se identifica con ninguno de los supuestos que justifican el carácter básico en la regulación de la red de distribución definidos en la STC 18/2011, de 3 de marzo (Fundamento Jurídico 10), entre los que destacan: la ordenación básica o primaria de la actividad de distribución para determinar las condiciones de tránsito de energía eléctrica por dichas redes; establecer la suficiente igualdad entre quienes realizan la actividad en todo el territorio; fijar las condiciones equiparables para todos los usuarios de la energía eléctrica; establecimiento de criterios de regulación de distribución de la energía atendiendo a zonas eléctricas con características comunes y vinculadas con la configuración de la red de transporte y de ésta con las unidades de producción; labores de coordinación que persigan la integración de la diversidad de las partes del sistema en el conjunto del mismo mediante la adopción por el Estado de medios y sistemas de relación, para asegurar la información recíproca, la homogeneidad técnica en ciertos aspectos y la acción conjunta de las autoridades estatales y autonómicas en el ejercicio de sus respectivas competencias. 
Consejo de Ministros al requerimiento de incompetencia formulado por la Generalitat, ni, finalmente, en las alegaciones formuladas por la Abogacía del Estado se justifica suficientemente la necesidad de imponer esta prohibición a través de una norma estatal. Por lo que se estaría impidiendo que las Comunidades Autónomas, en ejercicio de las competencias energéticas que tienen atribuidas, adopten medidas para la implantación de instalaciones comunes de autoconsumo en grandes edificios de viviendas, urbanizaciones o cualquier otro tipo de edificio complejo con elementos comunitarios donde puedan beneficiarse los usuarios que allí se encuentren.

Entiende el Tribunal que la prohibición contenida en el artículo 4.3 dificulta la consecución de objetivos de eficiencia energética y medioambientales contenidos en la normativa comunitaria: i) Directiva 2009/28/CE, del Parlamento Europeo y del Consejo, de 23 de abril, relativa al fomento del uso de energía procedente de fuentes renovables(67). ; ii) Directiva 2010/31/UE, del Parlamento Europeo y del Consejo, de 19 de mayo, relativa a la eficiencia energética de los edificios. La Directiva considera las instalaciones descentralizadas de producción de electricidad basada en fuente de energía renovable como medio esencial para garantizar que los edificios cumplen los requisitos mínimos de eficiencia energética que deben cumplir los EEMM. Además, la norma comunitaria fija para 2020 el objetivo de implantar edificios de consumo de energía casi nulo cubiertos por energía procedente de fuentes renovables producida en el mismo entorno; y iii) Directiva 2012/27/UE, del Parlamento Europeo y del Consejo, de 25 de octubre, relativa a la eficiencia energética (68). La Directiva se transpone a través del Real Decreto 56/2016, de 12 de febrero, en lo referente a auditorías energéticas, acreditación de proveedores de servicios y auditores energéticos y promoción de la eficiencia del suministro de energía (69). Cabe significar que esta norma también se refiere al concepto de edificios de consumo casi nulo que, por tanto, justifican la necesidad de la modalidad de autoconsumo compartido.

\section{Conclusiones}

Primera. El autoconsumo de electricidad nace en un nuevo paradigma energético que aproxima los centros de producción a las zonas de consumo $y$, en este sentido, emerge como una alternativa sólida al modelo

(67) DOUE núm. 140, de 5 de junio.

(68) DOUE núm.315, de 14 de noviembre.

(69) BOE núm. 38, de 13 de febrero de 2016. 
tradicional de suministro eléctrico, respecto del cual presenta grandes ventajas de carácter técnico, económico y medioambiental.

Segunda. Si bien es cierto que aquellas instalaciones de autoconsumo que no estén conectadas a la red quedan excluidas del ámbito de aplicación del RD 900/2015 y, por tanto, no están sujetas a las condiciones técnicas, administrativas y económicas aquí definidas, en la práctica, y como consecuencia del carácter intermitente de las fuentes de energía renovable destinadas a autoconsumo (principalmente sol y viento) aun no existen garantías tecnológicas de rigor que permitan al usuario dimensionar su instalación sin necesidad del respaldo que le ofrece la red.

Tercera. No se justifica que para la modalidad de autoconsumo tipo 1 el legislador haya definido un límite de potencia contratada no superior a 100 kW, máxime si tenemos en cuenta que el RD 1699/2011 define como de "pequeño tamaño" a determinadas tecnologías de hasta $1.000 \mathrm{~kW}$ de potencia. Entendemos que, con base a esta remisión normativa, el legislador debió al menos justificar la exclusión del tipo 1 para estas instalaciones por tener, presuntamente, un tamaño excesivo para el autoconsumo instantáneo.

Cuarta. La prohibición de que un mismo generador se conecte a la red interior de varios consumidores ha sido rechazada de forma unánime por la comunidad científica. Esta prohibición deja sin efecto, y vacío de contenido en la práctica, la categoría de autoconsumo definida en el artículo 9.1.d) LSE, esto es, la referida a cualquier otra modalidad de consumo de electricidad que provenga de una instalación de producción asociada a un consumidor.

Quinta. Si el autoconsumidor no contribuye a los costes y a la sostenibilidad económica del sistema, el resto de consumidores que no genera su propia electricidad pagaría no solo la parte relativa al coste de red que deja de pagar el autoconsumidor, sino también por un exceso de capacidad que éste introduce cuando vierte energía excedentaria a la red (tipo 2) en el sistema.

Sexta. Desde los comienzos de la regulación del autoconsumo en la LSE el legislador ha apostado por una atribución de competencias casi plena al Estado. Las CCAA han reaccionado impugnando el artículo 9 LSE y varios preceptos contenidos en el RD 900/2015, alegando como motivo principal que las condiciones técnicas, administrativas y económicas a que están sujetas las instalaciones no entran en el ámbito de la coordinación de la planificación general de la actividad económica de competen- 
cia estatal, no suponen aprovechamiento, por lo general, fuera del territorio autonómico $y$, en definitiva, desbordan el marco de actuación básico que compete al Estado.

Así pues, la STC 68/2017 se pronuncia por primera vez estimando algunas de las impugnaciones formuladas contra el RD 900/2015. En primer lugar, admite el carácter fuertemente ejecutivo de la función de control y seguimiento de los consumidores acogidos a cualquiera de las modalidades de autoconsumo y, por ello, su atribución competencial a la autonomía. Asimismo, concluye que la inscripción registral es un acto típicamente ejecutivo, por lo que las propuestas de inscripción, modificación y cancelación que emitan las CCAA deben ser aceptadas como vinculantes por el Estado. Por otro lado, anula la prohibición de que un mismo generador se conecte a la red interior de varios consumidores, sobre la base de que las instalaciones destinadas a más de un consumidor no tendrán la consideración de red de distribución (lo cual obligaría a ceder la instalación a la distribuidora, quedando abierto al acceso de terceros a ésta), sino que se trata de instalaciones de enlace que discurren por zonas de uso común pero que son propiedad del usuario particular. Tampoco se entiende la prohibición a la luz de los postulados contenidos en las normas comunitarias sobre consecución de objetivos de eficiencia energética y medio ambiente. Asimismo, el Tribunal no encuentra elementos de rigor que justifiquen el carácter básico en el establecimiento de esta prohibición, por lo que se impide que las CCAA opten por un modelo basado en el autoconsumo compartido.

\section{Bibliografía}

AGÚNDEZ BETELU, Miguel Ángel y MARTíNEZ SIMANCAS, Julián, en Energía eléctrica. Manual Básico para juristas, Editorial La Ley, 2014.

ALBA RÍOS, Juan José, ARAGONÉS AHNERT, Vanessa, BARQUÍN GIL, Julián y MOREDA DÍAZ, Eduardo, "La regulación del autoconsumo en España: ¿un impuesto al Sol?», en Revista de Obras Públicas: Órgano profesional de los ingenieros de caminos, canales y puertos, núm. 3584, 2017.

ALENZA GARCÍA, José Francisco, en La regulación de las energías renovables ante el cambio climático, Ed. Aranzadi, 2014.

ANDREU CASADEMONT, Frederic, "Autoconsumo instantáneo: ¿Qué proyectos de autoconsumo solar son rentables para las empresas?», en Era solar: Energías renovables, vol.32, núm. 183, 2014.

ARIÑO ORTIZ, Gaspar, DE LA CUÉTARA, Juan Miguel y DEL GUAYO CASTIELLA, Íñigo, «Teoría y práctica de las regulación para la competencia. 
Hacia un nuevo concepto de servicio público", en Regulación Económica. Lecturas Escogidas, Ed. Thomson, Madrid, 2012.

BALDWIN, Robert, SCOTT, Colin y HOOD, Christopher, en A Reader on Regulation, Ed. Oxford University Press, 1998.

BARCELÓ DOMÉNECH, Javier, "La incidencia de la fuerza mayor en el suministro de energía eléctrica: estudio de la cuestión en la jurisprudencia», en Práctica de Derecho de Daños, núm. 75, Sección de Estudios, 2009.

BECKER ZUAZUA, Fernando, "Prospectiva de la electricidad en España», en Estudios de economía aplicada, núm. 2 (ejemplar dedicado a: El sector de la energía eléctrica en España), 2011.

BONET SÁNCHEZ, Eduardo, "Transporte inteligente y ciudades digitales", en Política exterior, núm. 164, 2015.

BRAFF, William A., MUELLER, Joshua M. y TRANCIK, Jessika E., «Value of storage technolgies for wind and solar energy", en Nature Climate Change, núm. 6, 2016.

CHEVALIER, Michael, “¿Revolucionará Tesla la energía?: El fabricante estadounidense de coches eléctricos se diversifica con la fabricación de baterías de uso doméstico", en Alternativas económicas, núm.28 (septiembre), 2015.

COLMENAR SANTOS, Antonio, BORGE DÍAZ, David, COLLADO FERNÁNDEZ, Eduardo y ALONSO CASTRO GIL, Manuel, en Generación distribuida, autoconsumo y redes inteligentes, Editorial UNED, Madrid, 2015.

DEL GUAYO CASTIELLA, Íñigo, "Seguridad jurídica y cambios regulatorios (A propósito del Real Decreto-ley núm. 1/2012, de 27 de enero, de suspensión de los procedimientos de preasignación de retribución y de supresión de las primas para nuevas instalaciones de producción de energía eléctrica mediante fuentes de energía renovables», en Revista Española de Derecho Administrativo, núm. 156, 2012.

DEL GUAYO CASTIELLA, Íñigo, DOMINGO LÓPEZ, Enrique y LEIVA LÓPEZ, Alejandro D., «Régimen jurídico del auto-consumo en España. A propósito del Real Decreto 900/2015, de 9 de octubre», en Riesgo Regulatorio en las Energías Renovables II, ed. Aranzadi, 2017.

FABRA UTRAY, Jorge, "El marco actual y potencial del sistema eléctrico español para la generación distribuida de electricidad", en Revista de Obras Públicas: Órgano profesional de los ingenieros de caminos, canales y puertos, núm. 3584, 2017.

GOICOECHEA, Félix, «Renovables y autoconsumo, el Titánic español», en Electra, núm. 184, 2014.

GONZÁLEZ RÍOS, Isabel, "La incipiente regulación del autoconsumo de energía eléctrica: implicaciones energéticas, ambientales y urbanística», en Revista Vasca de Administración Pública, núm. 99, 2014. 
LARRAZA LÁZCOZ, Álvaro, "Autoconsumo compartido: por qué impulsarlo y cómo", en Revista de Obras Públicas: Órgano profesional de los ingenieros de caminos, canales y puertos, núm. 3584, 2017.

LEIVA LÓPEZ, Alejandro David, "Balance neto energético. Estado de la cuestión en EE.UU.», en Revista Aragonesa de Administración Pública, núm. 49-50, 2017.

MENDOZA LOSANA, Ana Isabel, «Trabas al autoconsumo de energía eléctrica», en Aranzadi civil-mercantil. Revista doctrinal, núm 3, 2016.

ORTIZ GARCÍA, Mercedes, «EI marco jurídico de la generación distribuida de energía eléctrica: autoconsumo, redes inteligentes y el derecho al sol». En Eficiencia energética y derecho/ Fernando García Rubio (dir.), Lorenzo Mellado Ruiz (dir.), Ed. Dykinson, S.L., Madrid, 2013.

RIVAS PEREDA, Carlos, "Autoconsumo y Smart Cities: Una introducción a tecnologías de futuro para la gestión eficiente de la energía", en $V$ Xornadas de Enxeñaría, Enerxía e Industria (XEEI): Eficiencia enerxética e innovación, Santiago de Compostela, 28 de xaneiro 2016 / BLANCO SILVA, Fernando y SARMIENTO DÍEZ, Oriol (dir. Congreso), 2016.

SIOSHANSI, Fereidoon P., en Future of Utilities. Utilities of the Future, ed. ACADEMIC PRESS, 2016.

SLAUGHTER, Andrew, "Almacenamiento de electricidad: tecnologías, impacto y perspectivas", en Cuadernos de energía, núm. 48, 2016. 
LABURPENA: Elektrizitatea energia berriztagarrien iturrietatik (adibidez, fotovoltaikotik) autokontsumitzen bada, maila askotan egiten zaie on sistema elektrikoari, planetari eta kontsumitzaileari. Sorkuntza banatuaren modalitate horrek abantailak sorrarazten ditu ingurumenean (karbono-gabetzeari laguntzen baitio), herrialdeko ekonomian (negozio-eredu berriak bultzatzen baititu), sistema elektrikoan oro har (garraioan gertatzen diren galerak murrizten baititu) eta, batez ere, azken kontsumitzailearengan (aurrezpenaz gain, energia-kudeaketaren kontrolari laguntzen baitio).

Horrela, bada, elektrizitatea sortzeko eredu horrek duen garrantziarengatik, autokontsumoan eta ingurune sozial eta teknologiko berrian oinarritzen baita, lan sistematiko bat egin dugu, non elektrizitatearen autokontsumo-eredu ezberdinen legezko erregulazioa aztertzen den (900/2015 Errege Dekretuan zehazten dira eredu horiek). Era berean, are zorrotzagoak izate aldera, egoki ikusi dugu gaur arte egon diren eskumen-arloko gatazkei buruzko azken doktrina-erabakiak aztertzea; batez ere, autokontsumo partekatuaren arlokoak.

GAKO HITZAK: Elektrizitatearen autokontsumoa. Sorkuntza banatua. Autokontsumo partekatua. Ekoizle eta kontsumitzaile. Autokontsumoaren erregistroa.

RESUMEN: El autoconsumo de electricidad a través de fuentes de energía renovable, como la fotovoltaica, constituye una alternativa que favorece al sistema eléctrico, al planeta y al consumidor a muchos niveles. Esta modalidad de generación distribuida proporciona ventajas en el medio ambiente - por su contribución a la descarbonización-, en la economía del país - favoreciendo nuevos modelos de negocio-, en el sistema eléctrico en su conjunto - ya que contribuye a la reducción de pérdidas en el transporte- $y$, sobre todo, para el consumidor final -favoreciendo no solo al ahorro, sino también al control de la gestión energética-.

Así, por la importancia de este modelo de generación de electricidad con autoconsumo en un nuevo entorno social y tecnológico, hemos elaborado un trabajo sistemático que analiza la regulación legal de las distintas figuras de autoconsumo de electricidad definidas en el Real Decreto 900/2015. Asimismo, y para una mayor exhaustividad y rigor, hemos considerado conveniente analizar los más recientes pronunciamientos doctrinales acerca de los conflictos competenciales acontecidos hasta la fecha y, destacadamente, en materia de autoconsumo compartido.

PALABRAS CLAVE: Autoconsumo de electricidad. Generación distribuida. Autoconsumo compartido. Prosumidor. Registro de autoconsumo.

ABSTRACT: The electricity self-consumption through renewable energy sources, such as photovoltaic power, is an alternative that favors the electricity system, the planet and the consumer at very many levels. This type of distributed generation provides advantages in the environment - with regard to the decarbonization-, in the country's economy - favoring new business models-, in the electricity system - with regard to the reduction of electricity losses in transport- and, above all, for the final consumer - promoting not only energy savings, but also energy management-. 
In this way, due to the importance of this electricity self consumption model, we have elaborated a systematic research work that analyzes the legal regulation of the different electricity self-consumption figures defined in the Royal Decree 900/2015.

As well, we have considered the opportunity to analyze the most recent doctrinal pronouncements about the potential conflicts over areas of competence occurred at the time and, in particular, the advances in terms of shared self-consumption.

KEYWORDS: Electricity self consumption. Distributed Generation. Shared self consumption. Prosumer. Self consumption registry office. 